\title{
Shared cerebral metabolic pathology in non-transgenic animal models of Alzheimer's and Parkinson's disease
}

\author{
Jelena Osmanovic Barilar ${ }^{1}$. Ana Knezovic ${ }^{1}$ - Ana Babic Perhoc ${ }^{1} \cdot$ Jan Homolak ${ }^{1} \cdot$ Peter Riederer $^{2,3}$. \\ Melita Salkovic-Petrisic ${ }^{1,4}$
}

Received: 17 December 2019 / Accepted: 24 January 2020 / Published online: 6 February 2020

(c) The Author(s) 2020

\begin{abstract}
Parkinson's disease (PD) and Alzheimer's disease (AD) are the most common chronic neurodegenerative disorders, characterized by motoric dysfunction or cognitive decline in the early stage, respectively, but often by both symptoms in the advanced stage. Among underlying molecular pathologies that PD and AD patients have in common, more attention is recently paid to the central metabolic dysfunction presented as insulin resistant brain state (IRBS) and altered cerebral glucose metabolism, both also explored in animal models of these diseases. This review aims to compare IRBS and alterations in cerebral glucose metabolism in representative non-transgenic animal PD and AD models. The comparison is based on the selectivity of the neurotoxins which cause experimental PD and AD, towards the cellular membrane and intracellular molecular targets as well as towards the selective neurons/non-neuronal cells, and the particular brain regions. Mitochondrial damage and coexpression of insulin receptors, glucose transporter- 2 and dopamine transporter on the membrane of particular neurons as well as astrocytes seem to be the key points which are further discussed in a context of alterations in insulin signalling in the brain and its interaction with dopaminergic transmission, particularly regarding the time frame of the experimental AD/ PD pathology appearance and the correlation with cognitive and motor symptoms. Such a perspective provides evidence on IRBS being a common underlying metabolic pathology and a contributor to neurodegenerative processes in representative non-transgenic animal PD and AD models, instead of being a direct cause of a particular neurodegenerative disorder.
\end{abstract}

Keywords Parkinson's disease · Alzheimer's disease $\cdot$ Non-transgenic animal models $\cdot$ Insulin resistant brain state · Cerebral glucose metabolism

\section{Introduction}

Parkinson's disease (PD) and Alzheimer's disease (AD) are the most common chronic neurodegenerative disorders. PD is characterized by classic motor dysfunction symptoms due

Melita Salkovic-Petrisic

melitas@mef.hr

1 Department of Pharmacology, University of Zagreb School of Medicine, Salata 11, 10000 Zagreb, Croatia

2 Center of Mental Health, Department of Psychiatry, Psychosomatics and Psychotherapy, University Hospital, Würzburg, Füchsleinstrasse 15, 97080 Würzburg, Germany

3 Department and Research Unit of Psychiatry, Institute of Clinical Research, University of Southern Denmark, Odense, Denmark

4 Institute of Fundamental Clinical and Translational Neuroscience, Research Centre of Excellence, Croatian Institute for Brain Research, University of Zagreb School of Medicine, Salata 12, 10000 Zagreb, Croatia largely to the loss of dopaminergic neurons in the substantia nigra pars compacta (SNpc) and intracytoplasmic aggregates of the presynaptic protein $\alpha$-synuclein ( $\alpha$-Syn) in formations called Lewy bodies (Davie 2008). On the other hand, AD is characterized by cognitive decline due to neuronal loss in the hippocampus (HPC) and temporal cortex, associated with pathological accumulation of aggregates of amyloid beta protein $(\mathrm{A} \beta)$ which forms extracellular plaques, and hyperphosphorylated tau protein which forms intracellular neurofibrillary tangles (Ballard et al. 2011). However, in the late stage of $\mathrm{PD}$, the majority of patients also manifest cognitive deficits and dementia (Caballol et al. 2007; Gratwicke et al. 2018), while motor symptoms which also include 
parkinsonism are present in the majority of patients with end stage AD (O'Keeffe et al. 1996; Ballard et al. 2011; Levin 2019). Despite different phenotypes, AD and PD share some common pathological features, e.g. oxidative stress and neuroinflammation (Han et al. 2018). Metabolic changes presented as insulin resistant brain state (IRBS) have recently gained more and more attraction as the pathophysiological core of AD (Hoyer 2004; Chen et al. 2014; Defelice and Ferreira 2002; de la Monte et al. 2014), particularly after the results of epidemiological studies demonstrating that type 2 diabetes mellitus (DM) is a risk factor for AD (Santiago and Potashkin 2013). However, some studies provided evidence that IRBS is also occurring in PD patients (Athauda and Foltynie 2016; Yang et al. 2018) and that DM is a risk factor for PD as well (Biosa et al. 2018). Consequently, clinical trials have been designed to test the therapeutic potential of antidiabetic drugs, in particular intranasal insulin (Claxton et al. 2015) and incretins (glucagon-like peptide-1 [GLP-1] analogues) in AD and PD patients (Athauda and Foltynie 2016; Femminella and Edison 2014). AD and PD seem like two streets going in parallel to the same direction called neurodegeneration with some overlap in their paths, and the nature of this overlap and the point at which it starts in the course of their pathophysiology seem to be the crucial questions.

The pathology in both AD and PD starts years before the first clinical symptoms and is difficult to trace in living humans, which is why animal PD and AD models are valuable tools. Although one should keep in mind that none of the animal models is able to fully recapitulate PD and AD pathology and symptoms, they are currently the only tool available to study the underlying pathophysiology mechanisms of these two diseases. Based on the involvement of gene manipulation in designing of the models, they can be classified in transgenic (genetic) and non-transgenic models generated by injection of different chemical, mainly neurotoxic compounds. Each group has advantages and disadvantages, but genetic models generally represent the early onset forms of familial $\mathrm{AD}$ and $\mathrm{PD}$, while the prevailing majority of $\mathrm{AD}$ and $\mathrm{PD}$ patients suffer from the sporadic and idiopathic forms of these diseases, respectively, for which nontransgenic animal models are more appropriate. This review aims to point out the similarities and differences in IRBS and related cerebral metabolic pathology between the nontransgenic PD and AD animal models. The representative non-transgenic $\mathrm{AD}$ and PD models will be compared from a perspective of similarities in the intracellular mechanism and target(s) of the toxicity of the compounds used to construct the models as well as the principles of their selectivity toward targeted neurons and non-neuronal cells. Finally, the alterations in insulin brain system and related interaction between insulinergic and dopaminergic transmission, particularly regarding the time frame of $\mathrm{AD} / \mathrm{PD}$ pathology appearance in correlation with cognitive and motor symptoms will be pointed out.

\section{Direct or indirect toxicity as a cause of the central insulin-related metabolic pathology}

Chemically induced non-transgenic animal models of AD and PD play an important role in defining critical diseaserelated mechanisms. Peripheral or central application of different substances, sometimes even in different parts of the brain (e.g. by intracerebroventricular [icv] or intrastriatal injection), with different mechanisms of action, results in different clinical symptoms which mimic those predominant in $\mathrm{AD}$ or PD patients. However, despite all these differences, these models also point to the common underlying molecular mechanisms of neuronal dysfunction (e.g. neuroinflammation, mitochondrial dysfunction and oxidative stress) when neurons and surrounding microglia and astrocytes are in stress following damage induced first by injection trauma and consequently by toxin-induced chemical reactions. It is still not clear whether neuroinflammation is the driven force of neurodegenerative disorders or is it a consequence of the metabolic dysfunction occurring earlier in the progression of diseases (Yin 2016). Based on its chemical structure, streptozotocin (STZ) might play multiple roles as a nonspecific cytotoxic compound which causes mitochondrial dysfunction, oxidative stress and neuroinflammation, as well as a selective metabolic toxin which causes damage to insulinproducing/secreting and insulin receptor (IR)-expressing cells (Correia et al. 2013; Eleazu et al. 2013). On the other side, 6-hydroxydopamine (6-OHDA) also demonstrates nonspecific toxicity by causing oxidative and mitochondrial damage and neuroinflammation, as well as selective toxicity to the dopaminergic neurons (Walsh et al. 2011). Despite of that, both e.g. STZ/AD and 6-OHDA/PD models seem to share IRBS and other insulin-related pathological features to a certain extent.

\section{Parkinson's disease models}

Although there are several neurotoxin-generated animal models of PD, the two golden standards are rats treated with 6-OHDA, and mice (or primates) treated with 1-methyl4-phenyl-1,2,3,6-tetrahydropyridine (MPTP) (Tieu 2011) which will be more closely elaborated in this review.

\section{Molecular targets responsible for selective toxicity}

MPTP and 6-OHDA share the same molecular target both at the cellular membrane (i.e. dopamine transporter [DAT], a target for selectivity, but not the direct toxicity) and 
intracellularly (mitochondria, the target of toxicity). The MPTP model is usually generated by a peripheral (subcutaneous, intraperitoneal) administration of MPTP (intranasal application has been recently introduced as well) which crosses the blood-brain barrier and is converted by monoamine oxidase- $\mathrm{B}$ to MPP+ in astrocytes, so it is MPP+ which is then a selective substrate for the high affinity DAT at the dopaminergic neuron axon terminals (Storch et al. 2004). Inside the dopaminergic neuron, MPP+ is actively transported into mitochondria where it interferes with the respiratory chain and inhibits complex I, inducing energy depletion and reactive oxygen species (ROS) production (Przedborski 2000). Since 6-OHDA does not cross the blood-brain barrier, the 6-OHDA model is generated by a central, stereotaxic administration (usually intrastriatal, but application to other regions is also possible) of 6-OHDA, which, as a hydroxylated analogue of dopamine, is also a selective substrate for DAT (Storch et al. 2004). Once inside the cell, it accumulates in the cytosol and is readily oxidized leading to ROS generation and ultimately, oxidative stressrelated cytotoxicity and mitochondrial fragmentation (Walsh et al. 2011; Solesio et al. 2013).

\section{Selective neuronal and regional toxicity}

DAT is selectively located at the dopaminergic neuron axon terminals concentrated in several brain regions, which leads to the prevailing selective accumulation of MPP+ and 6-OHDA in the nigrostriatal DAT-expressing dopaminergic neurons, particularly in the SNpc, found heavily involved in motor function but also in learned responses to stimuli (Da Cunha 2006). Dysfunctional mitochondria-based lesions in this region lead to primarily motor deficits but could also induce learning deficits similar to those found in PD patients (Da Cunha 2003). Intrastriatal 6-OHDA administration leads to depletion of catecholamine-expressing neurons and a selective inhibitor of noradrenergic transporter is generally used for protection of noradrenergic neurons, but even then, to a lesser extent, 6-OHDA is still capable of damaging noradrenergic neurons (Fulceri et al. 2006). This could be, at least partly, responsible for the lesions seen also in the locus coeruleus (Bonito-Oliva et al. 2014) as well as within the nucleus of the solitary tract (Falquetto et al. 2017) and the distinct cortical regions (Becker et al. 2018), associated with both central (cognitive impairment, depression, anxiety, olfactory deficit) as well as peripheral (cardiovascular, gastrointestinal) non-motor symptoms (Bonito-Oliva et al. 2014; Falquetto et al. 2017; Becker et al. 2018; Feng et al. 2019). MPTP neurodegeneration is also not exclusively limited to the nigrostriatal region, since MPTP was shown to bind to other brain regions as well (Javitch et al. 1985), and peripheral MPTP treatment was found to induce lesions in the hypothalamus (Gibb et al. 1986) which were associated with anorexia manifested prior to the appearance of motor deficits (Sandyk et al. 1990).

Additionally, different routes of neurotoxin administration could also account for extrastriatal alterations. It has been hypothesized that in the 6-OHDA model generated by central toxin administration, peripheral alterations in the gastrointestinal tract are indirect, as a consequence of central dopaminergic denervation and involvement of efferent vagal nerves (Pellegrini et al. 2016). On the other side, in the MPTP model, designed by peripheral toxin administration, peripheral pathology in the gastrointestinal tract could be a direct effect of the toxin on peripheral neuronal circuits, which spreads to the brain by afferent vagal nerves, and, additionally, an indirect effect, which results from the consequent central dopaminergic neurodegeneration, as reviewed by Pellegrini et al. (2016). This diversity in non-motor pathology which accompanies the common striatal dopaminergic deficits in non-transgenic PD models seems to fit the human PD condition for which the work of Braak et al. (2003) indicates that the neurodegenerative process could start in the peripheral nervous system, and progress towards the central nervous system in a caudal-to-rostral direction, so called bottom-up concept of propagation. However, others argue that, based on cases with intact vagal motor nucleus, the Braak staging cannot apply to all PD cases suggesting that there are different PD endophenotypes-clinical correlates (Jellinger 2019). This suggests that the neocortex may not necessarily be the final stage of bottom-up propagation. In view of IRBS, one could speculate that loss of energy/ IRBS might be a trigger that causes/facilitates cortico-striatal glutamatergic excitotoxicity with consequences like the degeneration of striatal dopaminergic synapses and $\alpha$-Syn pathology, and a retrograde striatal-nigral dopaminergic dysfunction and degeneration. From this perspective, based on the finding of cortical IRBS induced in rats by chronic exogenous corticosterone administration (Osmanovic et al. 2010), it could be further hypothesized that chronic stress accompanied by IRBS, might be a clinical/behavioural basis for a top-down propagation of neurodegeneration. A research demonstrating that cortical dysfunction could be the initial top-down alteration to affect vulnerable dopaminergic neurons, i.e. that cortical abnormalities are prodromal to motor symptoms, has been reviewed by Foffani and Obeso (2018). However, looking from another perspective, it has been suggested that parallel cellular pathologies in PD would give the first symptoms in the system with the lowest functional threshold due to selective vulnerability of different cell types/regions (Engelender and Isacson 2017). In line with that, there is a selective vulnerability of different brain regions to accumulated $\alpha$-Syn proposed to account for the pattern of PD progression, with nigral dopaminergic neurons being highly sensitive in this respect (Brooks 2010). 
Beside neurons, direct toxicity of 6-OHDA towards astrocytes has not been documented, whereas it can occur following MPTP administration due to the conversion of MPTP into the toxic MPP+ exclusively in astrocytes (Storch et al. 2004). Indirect effects of these neurotoxins on astrocytes are being more and more explored, since a growing body of literature indicates that astrocytes have an extremely important role in both recovery and aggravation of neurodegenerative disorders, including AD and PD (Maragakis and Rohtstein 2006). Despite common features shared throughout the brain, astrocytes show region-dependent density and vulnerability to injuries (Xu et al. 2001) and differences in expressing membrane structures (e.g. ion channels, transporters, etc.) involved in signalling (Bordey and Sontheimer 2000; Saab et al. 2012). In line with that, a recent in vitro study of 6-OHDA toxicity demonstrated huge differences in survival of dopaminergic neuronal cells in the presence of midbrain astrocytes in comparison to forebrain and hindbrain astrocytes, which was found related to 6-OHDA-induced NO release and consequent triggering of brain derived neurotrophic factor (BDNF) release from the neighbouring astrocytes (Datta et al. 2018).

\section{Direct toxicity towards the insulin receptor}

It is elusive whether the insulin-related metabolic changes observed in these PD models are associated with the damage solely in the nigrostriatal or/and in other brain regions, and secondly, whether they are the consequence of direct toxic effects or are induced indirectly by a lack of dopamine signalling. Considering direct toxicity, literature provides no direct evidence on the neuronal co-expression of DAT and insulin receptor (IR). However, there are reports indicating an extensive co-expression of tyrosine hydroxylase (the rate-limiting enzyme for DA synthesis used as a marker for dopaminergic neurons) with IR in the ventral tegmentum and substantia nigra (Figlewicz et al. 2003). These data suggest the presence of DAT-IR co-expression in striatal neurons and allow speculation that direct toxicity towards IR with a consequent dysfunction in insulinergic signalling might occur along with the reduction in dopaminergic signalling. Additionally, from the above mentioned 6-OHDA/MPTP-affected extrastriatal regions, the cortical and hypothalamic ones have been in particular highly enriched in insulin and IR (Hill et al. 1986; Schulingkamp et al. 2000) and, thus, also susceptible to damage by these toxins. Furthermore, it has been reported that insulin sensing by hypothalamic astrocytes which have a high IR expression (Przedborski 2000), co-regulates brain glucose sensing and systemic glucose metabolism (Garcia-Caceres et al. 2016). This indicates that neurotoxin-induced astrocyte damage due to MPP+ could be an alternative path of generating insulin-related metabolic dysfunction in the brain of MPTPinduced PD animal models.

\section{Indirect toxicity towards insulinergic signalling}

There are numerous reports demonstrating vulnerability of dopaminergic D1 and D2 receptors to MPTP and 6-OHDA toxicity (Falardeaur et al. 1988; Graham et al. 1990; Weihmuller et al. 1990; Woiciechowsky et al. 1995; Tanji et al. 1999; Vučković et al. 2010). In general, a significant decrease in D2 binding sites in the substantia nigra, seen up to 3 weeks post MPTP treatment in mice (Tanji et al. 1999), is then followed by a compensatory D2 receptor upregulation which lasts for about 3 months (Weihmuller et al. 1990). On the other hand, 3 months are required for the upregulation of D1 receptor binding sites which is still evident after 5 months (Weihmuller et al. 1990). Such a dysregulation in D1/D2 receptor expression in the nigrostriatal region may have a huge impact on the striatal insulin system since dopamine D2 receptors are modulators of insulin secretion and mice lacking these receptors display an impaired glucose metabolism (Garcia-Tornadu et al. 2010). Furthermore, striatal dopamine receptors modulate the expression of IR and insulin like growth factor-1 (IGF-1) receptor as well as glucose transporter-3 (GLUT-3) (Anitha et al. 2012). Small changes in dopamine levels in the early post- treatment phase could affect preferentially the activation of low (D1) versus high (D2) affinity receptors while the D2-mediated effects become more prominent in the advanced phase (Anitha et al. 2012). Evidence on the interplay between dopamine and insulin signalling (Kleinridders et al. 2015; Stouffer et al. 2015) suggests that neurotoxin-induced lack of dopamine is likely to result in indirect detrimental effects due to insulin dysfunction.

\section{Time course of the appearance of insulin signalling dysfunction and alterations in glucose metabolism in the brain}

The expression of IR and elements downstream its signalling pathway have been mostly explored in the 6-OHDA model and to a lesser extent in the MPTP model (Table 1). Both were found altered in the first week following the neurotoxin's application, although the regions explored were different; insulin binding to IR was decreased by $25 \%$ in the arcuate nucleus 7 days after 6-OHDA treatment (Wilcox et al. 1989), while decreased phosphorylation of enzymes downstream the IR signalling (phosphatidylinositol-3 kinase [PI3K], and protein kinase B [AKT]) was found 5 days following MPTP administration in the whole mouse brain, persisting up to 2 weeks (Hu et al. 2018; Liu et al. 2018). Dysfunctional IR signalling cascade in the 6-OHDA model was reported in the striatum; reduction of PI3K and AKT 


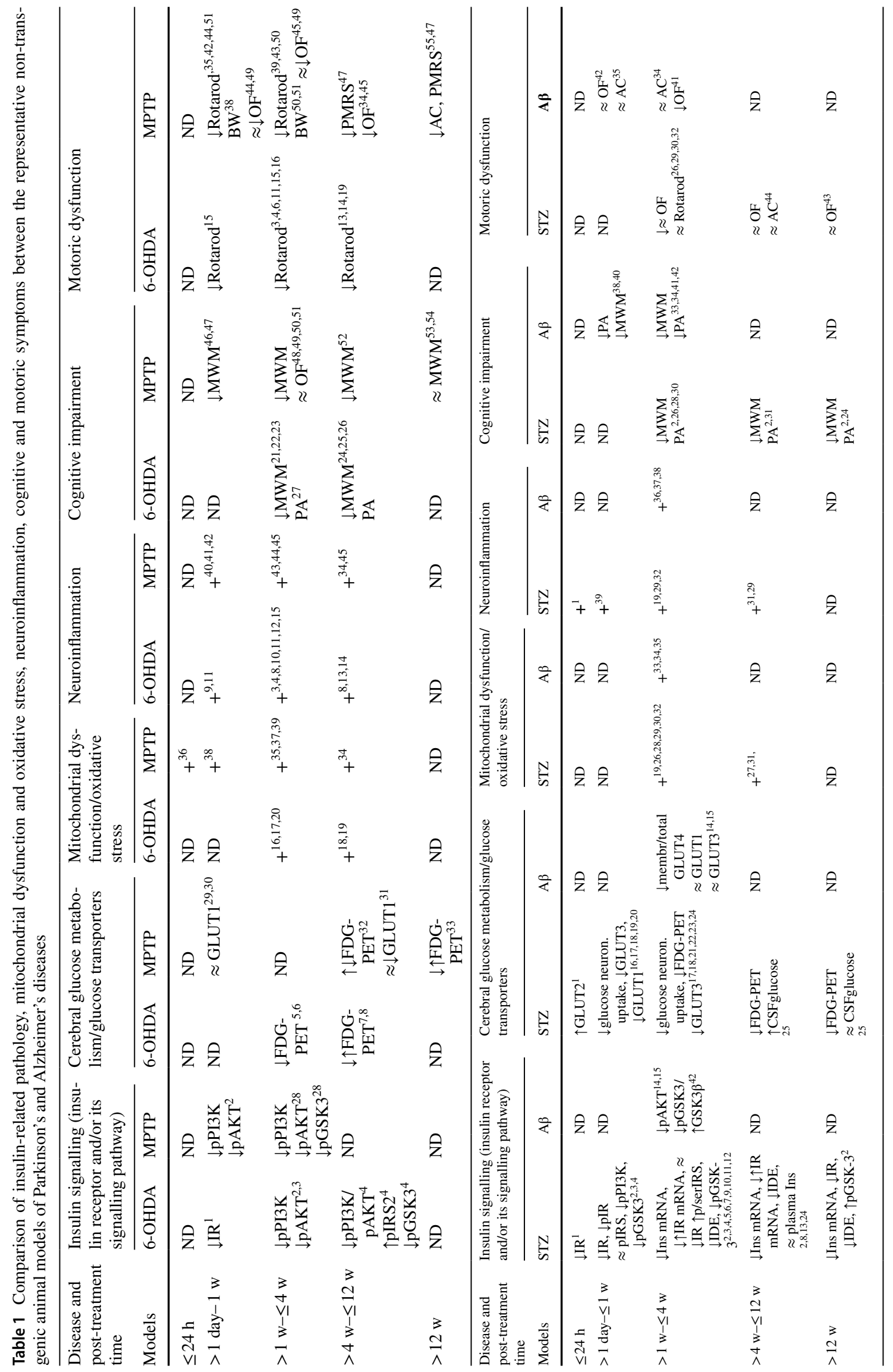




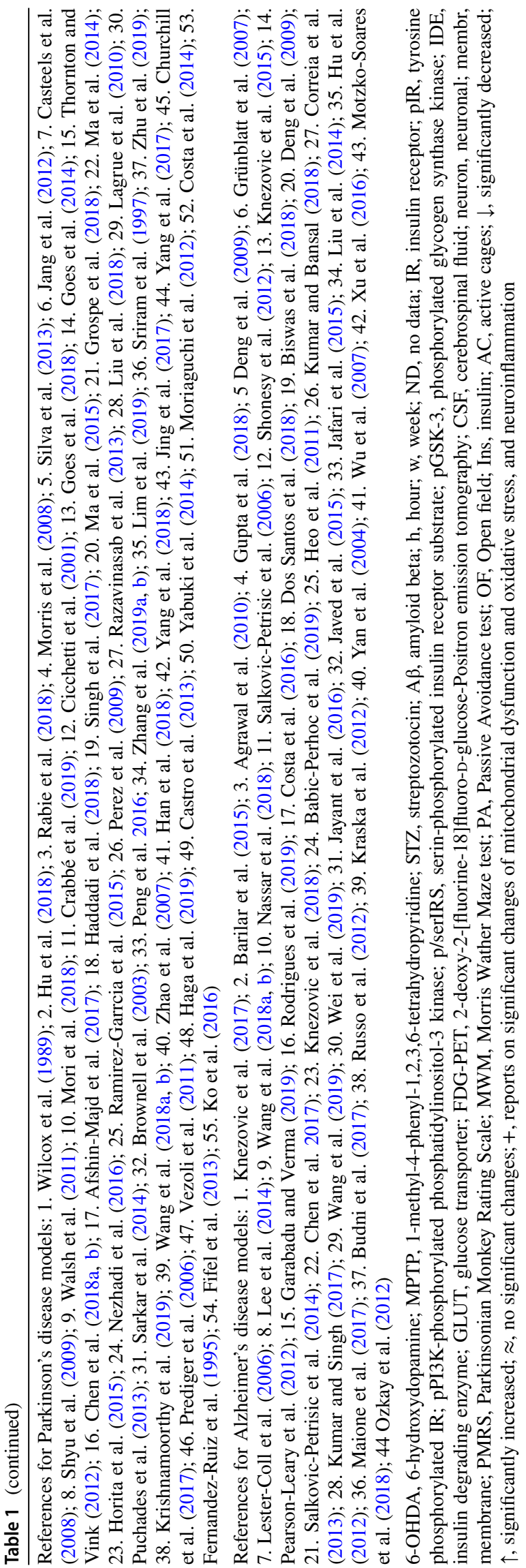

phosphorylation was found after 2 (Rabie et al. 2018) and 6 weeks (Morris et al, 2008), while increased striatal IRS2 serine phosphorylation, a marker of insulin resistance, was observed after 6 weeks (Morris et al. 2008). There is no data on IR signalling in the brain in periods $>1$ month following MPTP treatment (Table 1).

Changes in cerebral glucose metabolism, measured by ${ }^{18}$ F-fluorodeoxyglucose positron emission tomography (FDG-PET) were detected in 6-OHDA and MPTP models. The earliest time-point explored following neurotoxin treatment was 4 weeks after 6-OHDA application in rats, demonstrating decreased glucose uptake in the basal ganglia, olfactory bulb, primary motor cortex, substantia nigra, and tegmental nucleus (Jang et al. 2012; Silva et al. 2013). The finding of increased glucose uptake in the somatosensory cortex and ventral caudate-putamen in the same experiment indicates that alterations in cerebral glucose metabolism following 6-OHDA treatment are region-specific (Jang et al. 2012), as supported also by a research of Shyu et al. (2009). Another study in rats performed FDG-PET analysis 6-11 weeks following 6-OHDA treatment and demonstrated decreased glucose metabolism in the sensory-motor cortex and hippocampus, revealing also a positive correlation between the degree of DAT impairment and the change in hippocampal glucose metabolism (Casteels et al. 2008). FDG-PET studies performed in non-human primates (macaques) several months (exact time not specified) after MPTP administration, reported increased glucose uptake in the putamen/pallidum, thalamus, pons, medial frontal gyrus/ cingulate and sensorimotor cortex, and decreased glucose uptake in the posterior parieto-occipital cortex (Peng et al. 2016). Another study in macaques reported glucose metabolism to be decreased in the caudate, putamen, thalamus and primary motor cortex (range 35-50\%) and enhanced in the globus pallidus by $15 \%$, as measured 2-3 months post MPTP treatment (Brownell et al. 2003). These changes were accompanied by a decreased DAT content in the putamen and caudate $(60-65 \%)$ and no changes in D2 receptor level (Brownell et al. 2003). Glucose transporters play a key role in the regulation of cellular glucose uptake, but their research in these two PD models has been very modest with only few studies available on this topic in mice MPTP models (Table 1); two studies reported no changes in cerebral GLUT1 level in the acute phase (Lagrue et al. 2010; Puchades et al. 2013), while a study of Sarkar et al. (2014) demonstrated decreased GLUT1 expression in the striatum accompanied by decreased expression of DAT in the caudatus/putamen and the substantia nigra regions 5 weeks following MPTP treatment. 


\section{Alzheimer's disease models}

Unlike PD modelling, there is no golden standard in nontransgenic AD models due to the predominant use of transgenic mice models. However, among the chemically induced models, the two most frequently used are those with central administration of streptozotocin (STZ-icv) or A $\beta_{1-42}$, but the former has been far more extensively characterised (Table 1) (Kamat 2015; Facchinetti et al. 2018).

\section{Molecular targets of selective toxicity}

STZ is a selective substrate for the glucose transporter-2 (GLUT2) (Schnedl et al. 1994) which itself is also a target molecule for STZ toxicity (Gai et al. 2004). Exclusive selectivity of STZ for the GLUT2 isoform was explored generally in comparison to the GLUT1 isoform and not the other GLUTs, so one should not exclude STZ-icv toxicity towards GLUT3 whose expression was found decreased in the STZicv rat model (Salkovic-Petrisic et al. 2014) as well as the hippocampal neuronal stem cells in vitro (Sun et al. 2018).

Unlike STZ, exogenous (similar to endogenous) A $\beta$ peptide fragments seem to lack selectivity towards membrane molecular targets since the intracellular intake of $A \beta$ peptides is not operated via a selective transporter. Instead, three different pathways of its internalization have been proposed; for both $A \beta_{1-40}$ and $A \beta_{1-42}$ endocytic mechanisms seem to be the major ones although both could enter a neuron via the pore-forming protein perforin, while only $\mathrm{A} \beta_{1-42}$ was shown to enter via the receptor for advanced glycation end products (RAGE) (Lana et al. 2017). Endocytosis is two times more efficient for soluble $A \beta_{1-42}$ than for soluble $A \beta_{1-40}$ but both are predominantly taken up via clathrin- and dynaminindependent mechanisms (Wesen et al. 2017).

Regarding intracellular toxicity, both STZ and A $\beta$ fragments target the mitochondria (Correia et al, 2013; Narayan et al. 2014) but as an N-nitroso compound, STZ acts like an alkylating agent which damages DNA leading to mitochondrial dysfunction (Bolzán and Bianchi 2002). A massive production of ROS and nitric oxide, as well as decreased levels of ATP and glutathione (GSH) in the mice hippocampus were found already $24 \mathrm{~h}$ following STZ-icv administration of a $2 \mathrm{mg} / \mathrm{kg}$ dose (Amiri et al. 2017). Five weeks following a single bilateral STZ-icv administration of $3 \mathrm{mg} / \mathrm{kg}$ dose to rats, a decrease in the mitochondrial transmembrane potential, repolarization level, ATP content, respiratory state 3 , respiratory control ratio and $\mathrm{ADP} / \mathrm{O}$ index, and an increase in the lag phase of repolarization were observed (Correia et al. 2013). These changes were accompanied by a decrease in pyruvate and $\alpha$-ketoglutarate dehydrogenases and cytochrome c oxidase activities, and an increase in the susceptibility to calcium-induced mitochondrial permeability transition was found as well (Correia et al.
2013). Mitochondria are also intracellular targets of $A \beta$ as a consequence of their ability to form pores on the plasma membrane which then stimulate $\mathrm{Ca}^{2+}$ influx (Narayan et al. 2014). This leads to calcium-dependent ROS production, decrease in antioxidant GSH and also a profound increase in astrocytes' NADPH oxidase, resulting in induction of mitochondrial depolarization/deregulation (Angelova and Abramov 2016). $A \beta$ acts preferentially on astrocytes but causes neuronal death within 24 h. (Abramov and Duchen 2005).

\section{Selective neuronal and regional toxicity}

It is common knowledge that STZ is toxic to insulin-producing cells and damages the function of IR-expressing cells when given peripherally (Szkudelski 2001; Eleazu et al. 2013). Both types of cells are expressed in the brain (Plum et al. 2005) and are, therefore, assumed to be the targets of STZ administered icv (Salkovic-Petrisic et al. 2009; Kamat 2015). However, direct evidence of STZ entering into such cells is still lacking. The selectivity towards insulin-producing cells is based on the presence of membrane GLUT2 for which STZ is a selective substrate as mentioned above (Plum et al. 2005). GLUT2 is moderately expressed in the brain in a region-dependent manner, both in neurons and astrocytes (Arluison et al. 2004). Neuronal GLUT2 expression is possibly involved in glucose sensing, particularly in the hypothalamus, while in the hippocampus GLUT2 is supposed to participates in the regulation of neurotransmitter release and synaptic activity (Arluison et al. 2004; Jurcovicova 2014). STZ toxicity towards IR-expressing cells is not so clear at the periphery nor in the brain. One possibility might be the co-expression of GLUT2 and IR which has been demonstrated in the rat parieto-temporal cortex and hippocampus where most of the positive IR immunoreactivity was observed on the neuronal membranes, as shown by IR-NeuN co-localisation (Knezovic et al. 2017). Additionally, GLUT2-IR co-expression was demonstrated in the rat ependymal lining cells of the third ventricle in the hypothalamic region (Knezovic et al. 2017). Both GLUT2 and IR expression in these cells was found affected (increased and decreased, respectively) $1 \mathrm{~h}$ after STZ-icv application, providing thus an indirect evidence that GLUT2- and/or IR-expressing cells are the targets of STZ-icv toxic activity (Knezovic et al. 2017). Direct evidence of such a co-expression in other cells/regions is lacking so far but it seems very likely to occur in astrocytes (Dwyer et al. 2002; Plum et al. 2005). Similar to MPTP-induced effects, an in vitro study showed that STZ exerts a decrease in ATP level and decreased mitochondrial membrane potential not only in neurons but to a similar extent in astrocytes as well (Biswas et al. 2017). Furthermore, STZ in vitro treatment in rat astrocytes cell lines induced a significant decrease in IR mRNA and protein expression as well as a decrease in consequent 
phosphorylation of IRS- 1 , AKT, GSK-3 $\alpha$ and GSK-3 $\beta$ (Table 1), further followed by increased protein expression in amyloid precursor protein (APP), beta secretase-1 (BACE1), and A $\beta 1-42$ in astrocytes (Rajasekar et al. 2014).

Additionally, GLUT3-expressing neurons can be affected by STZ as mentioned above. Neuronal GLUT3, which is responsible for glucose transport into neurons (Simpson et al. 2008), and seems to also be a target of STZ toxicity (Salkovic-Petrisic et al. 2013), is found in the brain regions with dense neuronal synapses; the highest abundance in the rat brain is observed in the hippocampal and hypothalamic regions as well as in some layers of the cerebellum followed by high abundance in neuropil of some cerebral cortex layers, and substantia nigra (Gerhart et al. 1995). Glia cells do not express GLUT3 (Mantych et al. 1992). GLUT3 and IR co-expression has been confirmed in rat hypothalamic neurons (Kang et al. 2004), while there are no data on GLUT3 and GLUT2 co-expression in the brain.

Insulin signalling-related proteins, including IR, IRS-1, AKT, glycogen synthase kinase-3 $\beta$ (GSK3 $\beta$ ) and insulin degrading enzyme (IDE), were found co-expressed with choline acetyltransferase (ChAT) in the rodent brain (i.e. in hippocampal neurons), clearly indicating insulin signalling in cholinergic neurons (Wang et al. 2009). It is, therefore, important to point out that the density of ChAT-positive cells is significantly decreased in the rat hippocampus as well as in the basal forebrain, 3 weeks following STZ-icv treatment (Majkutewicz et al. 2016). Further research is needed to elucidate whether this is indeed a direct toxic effect of STZ on the cholinergic neurons in the region crucial for cognition. Furthermore, based on the hypothesis of a different pattern of neuronal loss in the subregions of the nucleus basalis of Meynert in the AD and PD condition (Liu et al. 2015), it would be worthy to compare the non-transgenic $\mathrm{AD}$ and $\mathrm{PD}$ models in this respect.

The problem with the construction of an $A \beta$ model lays in the fact that different $A \beta$ sequences (mostly $A \beta_{1-42}$ but other, shorter ones like $A \beta_{25-35}$ can be used as well) can be administered in different forms (soluble, fibrillary) either as a single injection into target areas of the hippocampus, cerebral cortex or basal forebrain nuclei, or as prolonged intracerebroventricular perfusion by osmotic minipumps, which can then lead to different effects (Harkany et al. 1999). At the current level of knowledge, it is not possible to determine which particular neurons are selectively targeted by exogenously administered $A \beta$ fragments. Furthermore, soluble $\mathrm{A} \beta$ was shown to compete with apoE for binding to the low-density lipoprotein receptor-related protein 1 (LRP1) on astrocytes (Verghese et al. 2013), indicating the possible mechanism of $A \beta$ intake into astrocytes. $A \beta$-induced formation of pores for stimulation of $\mathrm{Ca}^{2+}$ influx with consequent ROS production and mitochondrial damage happens only on the plasma membrane of astrocytes but not in neurons (Narayan et al. 2014).

Another approach to elucidate regional $A \beta$ targeted toxicity comes from preliminary experiments with peripheral $\mathrm{A} \beta$ administration in transgenic $\mathrm{AD}$ mice, aimed to assess its influence on the inherited $A \beta$ pathology and also to study A $\beta$ seeding activity (Eisele et al. 2009, 2010, 2014). In lack of literature data on non-transgenic AD models, following A $\beta$ spreading in transgenic mice models (which are not a focus of this review) might provide valuable information. The first experiments of Eisele et al. (2009) revealed that oral, intravenous, intraocular and intranasal administration of A $\beta$-containing extracts from aged APP2 23 transgenic mice (as well as from human AD brain in case of oral administration) resulted in no detectable induction of cerebral $\beta$-amyloidosis in APP23 transgenic mice as checked 3 or 6 months later. In parallel, central administration of these $A \beta$ extracts into different brain regions induced $A \beta$ deposition starting in the proximity of the injection site ( 3 months) and further spread into adjacent brain areas (6 months), suggesting that spreading can occur along fibre tracts (Eisele et al. 2009). Unlike the injection site-dependent parenchymal deposits, induction of $A \beta$ deposition in the vasculature was independent of the injection site (Eisele et al. 2009). Further research of the same group indicated that intraperitoneal application of transgenic mice A $\beta$ extracts to APP23 transgenic mice requires a higher concentration and a longer incubation interval to affect $A \beta$ deposition in the brain, compared to intracerebral administration (Eisele et al. 2010, 2014). This was manifested by formation of larger plaques and a substantially higher number of smaller plaques in the brain with no evidence for peripheral amyloid formation (Eisele et al. 2014). Interestingly, in the same set of experiments, peritoneal inoculation induced plaque seeding in all cortical regions without preferential sites, while intracerebral $\mathrm{A} \beta$ extract administration induced it locally at the site of injection (Eisele et al. 2014). Following a single intravenous injection of $\mathrm{A} \beta$ (isolated from AD patient's brain) to APP/ PS1 transgenic mice, the observed targets were only blood vessels as only cerebral amyloid angiopathy could have been observed within 180 days post injection, while amyloid plaque loads seemed unaffected (Burwinkel et al. 2018). Interestingly, in $\mathrm{A} \beta$-treated transgenic mice pronounced vascular amyloid deposition was found in the thalamus region, which was not seen either after the treatment with negative control extracts, nor in intact transgenic mice (Burwinkel et al. 2018). These findings provide further support to the hypothesis that $\mathrm{A} \beta$ most probably lacks a selective molecular target at the cellular/neuronal membrane and that further $A \beta$ pathology dissemination is very much dependent on the $A \beta$ entrance site. 


\section{Direct toxicity towards dopaminergic neurons}

Considering the AD-PD pathology interplay, and assuming that GLUT2 cell-expression is a toxicity target, it could be expected that there is a co-expression of GLUT2 and DAT, but there are no direct evidence for this in ex vivo histology analysis. Some rather indirect and elusive indication that such a co-existence should not be completely excluded comes from the in vitro study on the catecholaminergiccontaining N2a cells which express GLUT2, and whose upregulation leads to increased release of dopamine ( $\mathrm{Wu}$ et al. 2014). However, an extensive co-expression of tyrosine hydroxylase with IR in the ventral tegmentum and substantia nigra (Figlewicz et al. 2003) might suggest a direct toxicity of STZ towards the dopaminergic neurons as a base for PDlike pathology in the STZ-icv sAD model (Table 1).

No clear conclusion can be drawn for a direct toxicity of $A \beta$ towards dopaminergic neurons in the $A \beta$ model but such a possibility cannot be excluded merely due to a lack of evidence for $\mathrm{A} \beta$ selective toxicity towards particular cellular membrane structures.

\section{Indirect toxicity towards dopaminergic signalling}

Neurochemical analyses point to the changes in the dopaminergic neurotransmission in the brain of STZ-icv rat model observed 1 week after treatment with a low STZicv dose $(0.5 \mathrm{mg} / \mathrm{kg})$ as a decrease in the striatal dopaminergic D1 receptor density with no effect on D2 receptors (Šalković et al. 1995). This might be in line with timely different sensitivity of striatal D1 and D2 receptors on toxin treatment (Anitha et al. 2012). Changes in DA transmission in the STZ-icv rat model seem to be region-specific and STZ-dose- and post-treatment-dependent; an increase in DA content was observed after 1 week in the whole brain only with doses $>5 \mathrm{mg} / \mathrm{kg}$ (Lacković and Šalković 1990) while after 3 weeks, a huge decrease in DA content was reported in the hippocampus with a dose of $3 \mathrm{mg} / \mathrm{kg}$ (Arora and Deshmukh 2017; Kaundal et al. 2018) whereas at the same time point no change in DA content was seen in the striatum with a dose of $0.5 \mathrm{mg} / \mathrm{kg}$ (Ding et al. 1992). Furthermore, the expression of DAT mRNA gradually decreases in the course of post STZ-icv treatment time $(0.5 \mathrm{mg} / \mathrm{kg})$ in the ventral medial bundle reaching the level of statistical significance 4 weeks after the treatment, while, during that time it remained unchanged in the arcuate nucleus (SalkovićPetrisić and Lacković 2003).

Research on the dopaminergic transmission in $\mathrm{A} \beta$ models indicates changes in the early post-treatment phase as shown by a study of Mukhin et al. (2019) in rats treated icv with $\mathrm{A} \beta_{25-35}$ fragment in which the ability of neurons in the substantia nigra to secrete dopamine in the anterior dorsomedial striatum was reduced already during the hour following the moment of administration. Similar reduction in dopamine levels was observed in the rat prefrontal cortex 2 and $48 \mathrm{~h}$ following the icv injection of $A \beta_{1-42}$ (Trabace et al. 2007), and in the mice striatum 2 weeks after the $\mathrm{A} \beta_{1-42}$ treatment (Pandey et al. 2016).

\section{Time course of the appearance of insulin signalling dysfunction and alterations in glucose metabolism in the brain}

Considering the selective toxicity of STZ towards insulinproducing/secreting cells, it is to be expected that insulin signalling dysfunction has been more extensively explored in the STZ-icv model compared to the A $\beta$ model (Table 1). The earliest reported time-point of determination of IR expression was $1 \mathrm{~h}$ following STZ-icv administration of a single $1.5 \mathrm{mg} / \mathrm{kg}$ dose; mild decrease was found in IR immunoreactivity (mostly on neuronal membranes) in the parietal cortex while no changes were found in the temporal cortex and hippocampus (Knezovic et al. 2017). Additionally, decreased IR expression was found after $1 \mathrm{~h}$ also in the ependymal lining cells of the 3 rd ventricle in the hypothalamic region (Knezovic et al. 2017). Decreased IR expression in the rodents' hippocampus was more or less a consistent finding in the time-course of 6 months following STZ-icv treatment (Agrawal et al. 2010; Barilar et al. 2015; Gupta et al. 2018). However, no changes in IR expression was found 3 weeks after STZ-icv administration when analysis was done in homogenates of the whole cerebrum or cerebellum (Deng et al. 2009), indicating that changes are region-specific and, depending on the degree of change, might be lost when detecting in the brain as a whole. It is important to mention that changes were also observed at the gene level, seen as acute increase in IR mRNA after 2 weeks followed by a decrease later on at 9-month follow up (Barilar et al. 2015). In other studies, decreased IR mRNA expression was seen after 4 weeks not only in the hippocampus but also in the cortex, striatum and cerebellum (Gupta et al. 2018), and after 3 months in the frontoparietal cortex (Grünblatt et al. 2007). Additionally, in vitro studies showed that STZ decreases expression of both IR protein and mRNA in astrocytes (Rajasekar et al. 2014).

Looking upward of the IR signalling to the level and synthesis of insulin in the rat brain, which was found to occur in neurons and not in glia (Schechter et al. 1988), the earliest time-point of insulin mRNA assessment was 2 weeks following intracerebral STZ administration to young rat pups, in which decreased insulin gene expression was observed in the temporal lobe (Lester-Coll et al. 2006) (Table 1). In adult rats, insulin mRNA expression in the hippocampus was found unchanged after 2 and 4 weeks, but was significantly decreased in periods $>1$ month following STZ-icv treatment (Barilar et al. 2015), which could be related to 

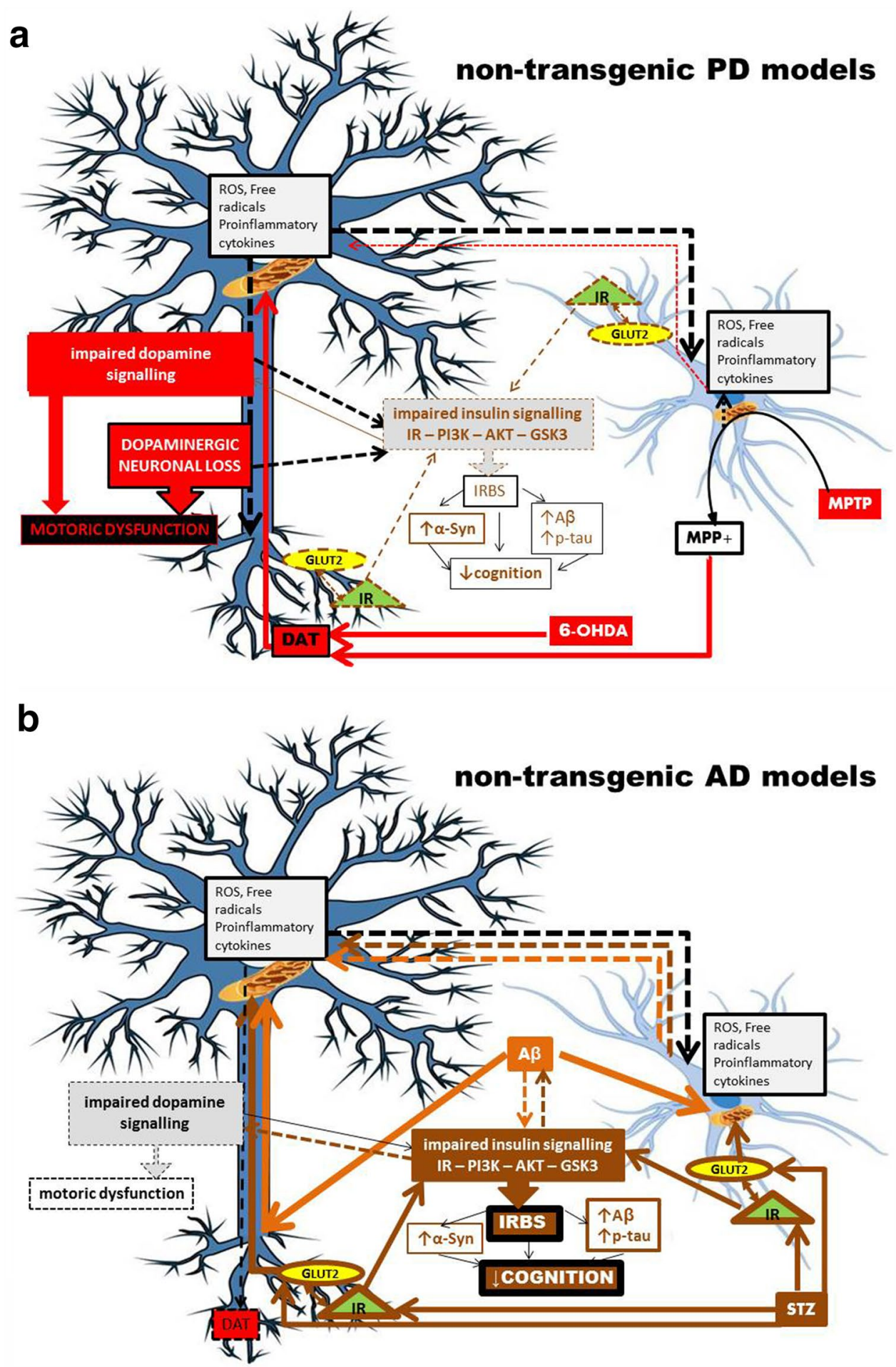

a lesser sensitivity of the mature neurons to STZ toxicity (Isaev et al. 2018). Decreased insulin mRNA expression was also observed in different brain regions of monkeys, including the frontal cortex and hippocampus, 5 months following STZ-icv administration (Lee et al. 2014). Considering the elements downstream the IR signalling cascade in the STZicv model, dysfunctionality was observed rather consistently across the studies of different research groups and at different time-points from 1 week up to 9 months post-STZicv treatment (Table 1). Different parameters ranging from decreased tyrosine phosphorylation of IR, through serine phosphorylation of IRS1, decreased PI3K and AKT phosphorylation, to consequently increased GSK3 activity, were explored and demonstrated starting from 1 week onward 
४Fig. 1 Proposed mechanism of central insulin resistance as a common pathological feature in non-transgenic models of Parkinson's and Alzheimer's disease. In 6-OHDA- and MPTP-induced PD models (a) impaired dopaminergic signalling is the predominating severe pathological event due to the selectivity of these compounds for entering DAT-expressing dopaminergic neurons. The extent of dopaminergic signalling impairment accompanied by dopaminergic neuronal loss (particularly in the substantia nigra pars compacta) is large enough to cause motoric dysfunction. The molecular mechanism(s) of toxicity is related to mitochondrial damage, generation of oxidative stress and proinflammatory cytokines which may further damage the respective neuron but also the neighbouring astrocytes. However, due to the dopamine-insulin interaction based on the co-expression of their major signalling parameters, disturbed dopamine signalling may be, to a lesser extent, transduced to insulin signalling downstream the insulin receptor pathway, as a secondary, collateral damage. The resulting insulin resistance may further lead to cognitive impairment, but also to the accumulation of Alzheimer's (amyloid beta and hyperphosphorylated tau protein) and Parkinson's (alpha-synuclein) pathological hallmarks. In the condition generated by STZ administration which induces Alzheimer's disease (b), the insulin receptor and its signalling pathway are the primary, direct targets which lead to the insulin resistance state as a predominant pathological effect, both in neurons and neighbouring astrocytes expressing the targets. Therefore, it is to be expected that the extent of insulinergic signalling impairment is large (larger than induced by 6-OHDA/MPTP), because cognitive decline is pronounced, associated with pathological accumulation of the respective misfolded proteins. Damaged astrocytes can further destroy neighbouring neurons and vice versa, STZinduced mitochondrial damage in the neuron can affect neighbouring astrocytes. In this scenario, due to the insulin-dopamine interplay, impaired insulin signalling can be transduced to dopaminergic signalling as a secondary, collateral damage (without severe dopaminergic neuronal loss), which can possibly be reflected in some motoric dysfunction expressed to a much lesser extent than in PD models. $P D$ Parkinson's disease, $A D$ Alzheimer's disease, 6-OHDA 6-hydroxydopamine, MPTP 1-methyl-4-phenyl-1,2,3,6-tetrahydropyridine, $M P P+, 1$-methyl-4-phenylpyridinium, $S T Z$ streptozotocin, $A \beta$ amyloid $\beta, \alpha$-Syn $\alpha$-synuclein, DAT dopamine transporter, GLUT2 glucose transporter-2, $I R$ insulin receptor, $P I 3 K$ phosphatidylinositol-3 kinase, $A K T$ protein kinase $\mathrm{B}, G S K 3$ glycogen synthase kinase-3, p-tau phospho tau protein, ROS reactive oxygen species, solid line direct effect, dashed line indirect effect

following STZ-icv treatment (Table 1) (Salkovic-Petrisic et al. 2006; Deng et al. 2009; Shonesy et al. 2012; Barilar et al. 2015; Gupta et al. 2018; Nassar et al. 2018; Wang et al. 2018a, b). A 9-month follow up study indicated that neurochemical changes related to insulinergic signalling in the hippocampus, including the alterations in IDE and gene expression, seem to follow a biphasic pattern (Knezovic et al. 2015; Barilar et al. 2015); an acute response emphasized up to 1 month post-treatment, followed by a slow progressive chronic phase seen at $>3$ month time-points, which positively correlated with cognitive impairment (Knezovic et al. 2015). Insulin levels measured in cerebrospinal fluid (CSF) and plasma showed some mild variations seen only in the acute phase (Babic Perhoc et al. 2019).

Research on insulin signalling dysfunction in the brain of the $\mathrm{A} \beta_{1-42}$ model is modest, revealing decreased phosphorylation of AKT in the rat hippocampus 2 weeks following
$\mathrm{A} \beta_{1-42}$ treatment (Table 1) (Pearson-Leary et al. 2012; Garabadu and Verma 2019).

STZ and $A \beta_{1-42}$ models also display changes in cerebral glucose metabolism detected by FDG-PET and glucose uptake studies as well as by analysis of GLUTs, which were all more extensively explored in the STZ-icv model (Table 1). The earliest time-point measured was $1 \mathrm{~h}$ after a single dose of STZ-icv when an increase of GLUT2 expression was found in the hippocampus and hypothalamus with no changes in cortical regions (Knezovic et al. 2017). The next time-point was $48 \mathrm{~h}$ after the treatment when decreased glucose uptake by neurons was recorded (Rodrigues et al. 2019). In the course of time, changes in neuronal glucose uptake showed persistent decrease after 1 and 4 weeks (Costa et al. 2016; Dos Santos et al. 2018). FDG-PET studies in rats detected glucose hypometabolism starting from 3 weeks following STZ-icv treatment onward (Chen et al. 2018a, b; Knezovic et al. 2018; Babic Perhoc et al. 2019), which was observed also in STZ-icv treated monkeys after 6 and 12 weeks (Heo et al. 2011). Regarding the alterations of GLUTs, consistent findings on decreased levels of GLUT1 and GLUT3 were detected in the brain of the STZ-icv rat model starting from 1 week following treatment (Table 1) (Deng et al. 2009; Biswas et al. 2018). GLUT3 was found additionally decreased 1 month after STZ treatment (Table 1) (Salkovic-Petrisic et al. 2014).

First alterations of cerebral glucose metabolism in the A $\beta 1-42$ model were recorded 2 weeks following the treatment when decreased levels of glucose were detected in hippocampal neurons and increased concentration was observed in the cerebrospinal fluid (Table 1) (Pearson-Leary et al. 2012). The same study found no changes in GLUT1 and GLUT3 expression in the hippocampus but translocation of the insulin-sensitive GLUT4 transporter from the intracellular compartment to the membrane was decreased (Pearson-Leary et al. 2012), as reported also by Garabadu and Verma (2019).

\section{Insulin and dopamine signalling interplay in non-transgenic ad and PD models}

At the molecular level, PD (6-OHDA/MPTP)- and AD (STZ/ $\mathrm{A} \beta_{1-42}$ )-causing neurotoxins share mitochondria as the same intracellular target of their toxicity (Walsch et al. 2011), while their targets greatly differ at the cellular membrane; PD-causing neurotoxins are both linked to DAT (Storch et al. 2004), whereas AD-causing ones are either linked to GLUT2 and/or IR (STZ) (Gai et al. 2004; Knezovic et al. 2017), or have no known preferences for membrane targets $\left(\mathrm{A} \beta_{1-42}\right)$. These differences are expected to lead to different selectivity towards particular neurons or non-neuronal cells which express DAT, GLUT2 or IR. Although at first sight 
this might imply that 6-OHDA/MPTP on one side, and STZ and $\mathrm{A} \beta_{1-42}$ each on other sides, will target different neurons, literature does not entirely support this assumption. On the contrary, it suggests that, not only some neurons seem to co-express PD- and AD-neurotoxin targets (Fieglewicz et al. 2003), but such targets co-expression is seen additionally in non-neuronal cells like astrocytes (Przedborski 2000; Arluison et al. 2004), and astrocytes may then consequently damage neighbouring neurons (Fig. 1). In this regard, it could be speculated that a difference lays in the order in which particular cell types are being damaged with three possible scenarios; (1) neurons are attacked first which consequently causes damage to the neighbouring astrocytes, (2) astrocytes are the primary targets which then injure the neighbouring neurons, (3) neurons and astrocytes can be independently damaged in parallel. Due to selective targeting of DAT at the neuronal membrane, the first scenario most likely applies to the effects induced by 6-OHDA and MPTP. The second and the third scenarios seem to apply to STZ- and A $\beta_{1-42^{-}}$ induced toxicity. These two compounds enter the neurons but also the astrocytes which predominately express targets (STZ/GLUT2, IR) at the membrane (Dwyer et al. 2002; Arluison et al. 2004), or the toxin $\left(A \beta_{1-42}\right)$ has preference for the astrocyte's pore-stimulated $\mathrm{Ca}^{2+}$ influx with consequent astrocyte mitochondrial damage (Verghese et al. 2013). Therefore, keeping in mind the astrocytes' region-dependent density and vulnerability to injuries (Xu and Zhang 2011), as well as differently expressing membrane signalling structures (Bordey and Sontheimer 2000), this again provides plausible evidence that, besides the dose, the site of central STZ/A $\beta_{1-42}$ application plays a key role in determining the final toxic effect.

Since early changes have not been fully characterized in $\mathrm{AD}$ and PD models discussed here, and because there are other pathological processes going on in $\mathrm{AD}$ and $\mathrm{PD}$ that have not been taken into account here (e.g. apoptosis and autophagy disturbances, etc.), it is difficult to draw a conclusion on the order of dysfunction appearance between the insulin and dopamine signalling and the causal relationship between the two of them. Published data indicates that both insulin and dopamine signalling have been impaired in $\mathrm{AD}$ models during the first hour following neurotoxin administration; IR expression is decreased in the cortex and hypothalamus, and accompanied by increased GLUT2 expression in the hippocampus and hypothalamus of the STZ-icv model (Knezovic et al. 2017), while at the same time-point dopamine levels are found decreased in the substantia nigra in the $A \beta$ model (Mukhin et al. 2019). Such a comparison is not possible in PD models since insulin signalling in the brain has not been explored earlier than 7 days following 6-OHDA/MPTP treatment (Wilcox et al. 1989). Additionally, from that time-point onward, impaired insulin and dopaminergic signalling in the brain (and in the striatum and hippocampus in particular) have been detected both in AD and PD models (Salkovic-Petrisic et al. 2006; Lester-Coll et al. 2006; Grünblatt et al. 2007; Morris et al. 2008; Deng et al. 2009; Agrawal et al. 2010; Shonesy et al. 2012; Lee et al. 2014; Barilar et al. 2015; Knezovic et al. 2015, 2017; Hu et al. 2018; Rabie et al. 2018; Gupta et al. 2018; Wang et al. 2018a, b; Nassar et al. 2018). On one side, there is decreased IR expression in astrocytes and neurons already $1 \mathrm{~h}$ after STZ application, and STZ-induced mitochondrial damage manifested during $24 \mathrm{~h}$ following STZ-icv treatment (Amiri et al. 2017; Knezovic et al. 2017). On the other side, insulin mRNA in adult rats cannot be detected within 2 weeks post-STZ-icv treatment (Barilar et al. 2015). Therefore, it seems likely that IR signalling is the primary pathological event following STZ-icv treatment, while a decrease in insulin synthesis comes as a secondary pathology, contributing to aggravation and progression of neurodegeneration. This hypothesis is in line with the findings of disturbed PI3K/AKT signalling pathway in neurodegeneration (as reviewed elsewhere, Rai et al. 2019). The impaired signal is further transduced to GSK3 enzyme involved in dysregulation of $\mathrm{AD}$-linked $\mathrm{A} \beta$ homeostasis and tau hyperphosphorylation (Martinez and Perez 2013), but also in $\alpha$-Syn-mediated neurodegeneration in PD (Yang et al. 2018). 6-OHDA- and MPP+-induced neurodegeneration is associated with increased GSK3 $\beta$ activity also in in vitro PD models (Wu et al. 2007). All this strongly suggests that impairment in the IR signalling cascade with a consequent IRBS condition is, actually, not unique only to $\mathrm{AD}$, but instead, can be considered a common underlying mechanism in neurodegenerative disorders as evidenced in non-transgenic PD and AD models (Fig. 1).

This hypothesis on the common IRBS role as a contributor to neurodegeneration in $\mathrm{AD}$ and $\mathrm{PD}$ condition strongly agrees with a recently proposed role of $\alpha$-Syn in neurodegenerative disorders (Riederer et al. 2019). For a long time, $\alpha$-Syn has been thought of as a specific pathological hallmark of PD. However, a growing body of evidence has emerged showing its co-localisation and synergistic effects with other proteins prone to pathological misfolding (e.g. $\mathrm{A} \beta$ and hyperphosphorylated tau protein) in neurodegenerative disorders other than PD, which finally led to a conclusion that $\alpha$-Syn is more likely a non-specific bystander and a contributor to neurodegeneration in general, than a specific etiopathogenic factor of PD (Riederer et al. 2019).

It might be speculated that in the case of IR being the primary target of toxicity (e.g. like in the STZ-icv model) and due to the widely spread IR expression in the brain on neurons, astrocytes, endothelial and inflammatory cells, the IRBS condition and its consequences would dominate, while dopaminergic signalling dysfunction could be below the threshold for clinical manifestations, as supported by, in general, lack of significant (or only a mild) locomotor 
impairment in STZ-icv treated rats (Table 1, Fig. 1). Considering the important role of insulin in the brain in synaptic plasticity, learning and memory functions, such a predomination of IRBS might be reflected in cognitive impairment consistently seen in the STZ-icv model from the 2-week time point onward (Knezovic et al. 2015), and even at earlier time-points in the $A \beta$ model (Table 1) (Schmid et al. 2017). Recent evidence suggests that the neurotoxic properties of $A \beta$ and related cognitive impairment are mediated by oxidative stress, neuroinflammation but also by the disturbed PI3K/AKT/GSK3 signalling pathway (Morroni et al. 2016; Schmid et al. 2017; Amin et al. 2015). Additionally, decreased immunoreactivity for the vesicular acetylcholine transporter (a marker of cholinergic neurons) was observed already 1 week after $A \beta$ fragments treatment in 6-7 weeksold rats (Zussy et al. 2011) as well as cholinergic neuronal loss found 3 weeks following STZ-icv administration to rats (Majkutewicz et al. 2016), which could contribute to cognitive impairment in both models. Although dopamine release is acutely disturbed after $\mathrm{A} \beta$ fragments administration (Trabace et al. 2007), the impact of this seems not to be capable of triggering significant locomotor deficits, at least not in observational periods explored so far (Guerra de Souza et al. 2018).

Cerebral glucose metabolism, explored and found decreased already within the first post-treatment week in the STZ-icv model, and at $>1$-week time-points in $\mathrm{A} \beta / \mathrm{AD}$ and in both PD models (Table 1) (Chen et al. 2018a, b; Knezović et al. 2017; Babic Perhoc et al. 2019; Jang et al. 2012; Silva et al. 2013) certainly contributes to cognitive impairments seen in these models, as does the glucose hypometabolism observed in the brain of AD patients (Chen and Zong 2013). Furthermore, GLUT changes seen in these non-transgenic models are quite resembling to those found in $\mathrm{AD} / \mathrm{PD}$ patients, e.g. decreased levels of GLUT3 were found in the brain of AD patients post mortem (An et al. 2018; Liu et al. 2009) accompanied by an increase in GLUT2 expression which most likely occurs in astrocytes (Liu et al. 2008).

Following administration of DAT-targeting neurotoxins, IR seems to be a collateral damage due to the evidence of IR co-expression with tyrosine hydroxylase, a marker for dopaminergic neurons (Figlewicz et al. 2003). Thus, dopaminergic loss-related signalling dysfunction would be predominant over IRBS, and evidently manifested by PD-like motoric symptoms (Table 1). However, the impact of disturbed IR signalling pathway seems to be strong enough to trigger certain cognitive impairments, as observed in 6-OHDA/MPTP models starting from 2 weeks after treatment, and onwards (Castro et al. 2013; Grospe et al. 2018).

Trans-disciplinary preclinical/clinical research indicates that insulin signalling influences dopamine availability and turnover (Kleinridders et al. 2015; Stouffer et al. 2015) and a recent post-mortem study in the brains of mentally ill patients provided evidence that the expression of dopamine signalling genes was mediated by insulin signalling genes (Mansur et al. 2019). Additionally, human data points to changes in dopaminergic system found in $\mathrm{AD}$ patients postmortem; significantly lower levels of DA, its precursor and its metabolite were found in the striatum and additionally in the cingulate gyrus, amygdala and raphe nuclei (Storga et al. 1996). These reductions in DA level correlated well with the duration of AD (Pinessi et al. 1987), and decrease in DAT expression (Allard et al. 1990). Furthermore, the number of striatal dopaminergic D1/D2 receptors was found decreased in AD patients (Pizzolato et al. 1996). In line with that, it is not unexpected that $\mathrm{AD}$ patients develop also symptoms of motor dysfunction (O'Keeffe et al. 1996; Albers et al. 2015). It seems likely that the reasons for motor dysfunction being generally not observed in STZ/A $\beta$ animal models of sporadic $\mathrm{AD}$, could be related to a too short post-treatment observational period, and to the lack of gene-environmental interactions that have been suggested to play a role in $\mathrm{AD}$ and $\mathrm{PD}$ onset, development and progression (Landrigan et al. 2005).

\section{Conclusion}

Although a growing body of evidence suggests that the prevailing sporadic $A D$ and idiopathic $P D$ are fundamentally metabolic diseases with characteristic neurodegenerative processes possibly being caused by IRBS and metabolic dysfunction (Hoyer 2004; Defelice and Ferreira 2002; de la Monte et al. 2014; Chen et al. 2017; Bloom et al. 2018; Athauda et al. 2016; Schelp et al. 2017; Yang et al. 2018); the cause(s) and characterisation of these metabolic alterations are still unknown. One way to understand the metabolic etiopathogenesis of sporadic/idiopathic AD and PD is to explore the onset, development and time-course of insulin signalling dysfunction and glucose metabolism in the brain of animal models that mimic these human diseases. These models are generated by administration of particular neurotoxins, some of which could be considered as environmental toxins (e.g. MPTP as a recreational drug (Lau and Meredith 2003), and STZ as chemically related to nitrosamine-based food preservative (Tong et al. 2009)), and thus, more likely to mimic real-life exposure which might be associated with the increased risk for developing sporadic/idiopathic forms of $\mathrm{AD}$ and $\mathrm{PD}$. In line with that, it is of utmost importance to detect toxicity targets of these neurotoxins at the molecular, cellular and tissue/regional level and assess where and to which extent do they overlap.

Sharing of the molecular mechanisms (mitochondrial damage) and co-expression of the molecular targets (IR, GLUT2, DAT) on membranes of particular neurons as well as astrocytes might be the underlying mechanism for insulin-related metabolic alterations present in both $\mathrm{AD}$ 
and PD non-transgenic models. Dysfunction in IR and its downstream PI3K/AKT/GSK3 signalling pathway seems to be a key pathology shared by the models (Table 1), occurring either as a primary toxic event, and, thus, expressed to a larger extent with consequently severe cognitive deficits in non-transgenic AD models, or as a collateral damage, expressed to a lesser extent and leading to less dominant cognitive impairment in non-transgenic PD models (Fig. 1). Based on that, IRBS could be considered a common metabolic pathology in the representative non-transgenic animal models of both AD and PD which, instead of being a cause, seems to be a common contributor to neurodegenerative processes. Further research is needed to provide in depth characterization of the brain insulin and dopamine signalling interaction in particular models at the molecular, cellular and regional level, for more successful animal-to-human data translation.

Acknowledgements Supported by the Croatian Science Foundation (Project IP-2018-01-8938). This publication was co-financed by the Scientific Centre of Excellence for Basic, Clinical and Translational Neuroscience (project "Experimental and clinical research of hypoxicischemic damage in perinatal and adult brain"; GA KK01.1.1.01.0007 funded by the European Union through the European Regional Development Fund).

\section{Compliance with ethical standards}

Conflict of interest The authors declare that they have no conflict of interest.

Open Access This article is licensed under a Creative Commons Attribution 4.0 International License, which permits use, sharing, adaptation, distribution and reproduction in any medium or format, as long as you give appropriate credit to the original author(s) and the source, provide a link to the Creative Commons licence, and indicate if changes were made. The images or other third party material in this article are included in the article's Creative Commons licence, unless indicated otherwise in a credit line to the material. If material is not included in the article's Creative Commons licence and your intended use is not permitted by statutory regulation or exceeds the permitted use, you will need to obtain permission directly from the copyright holder. To view a copy of this licence, visit http://creativecommons.org/licenses/by/4.0/.

\section{References}

Abramov AY, Duchen MR (2005) The role of an astrocytic NADPH oxidase in the neurotoxicity of amyloid beta peptides. Philos Trans R Soc Lond B Biol Sci 360:2309-2314

Afshin-Majd S, Bashiri K, Kiasalari Z, Baluchnejadmojarad T, Sedaghat R, Roghani M (2017) Acetyl-l-carnitine protects dopaminergic nigrostriatal pathway in 6-hydroxydopamine-induced model of Parkinson's disease in the rat. Biomed Pharmacother 89:1-9

Agrawal R, Mishra B, Tyagi E, Nath C, Shukla R (2010) Effect of curcumin on brain insulin receptors and memory functions in STZ (ICV) induced dementia model of rat. Pharmacol Res $61: 247-252$
Albers MW, Gilmore GC, Kaye J et al (2015) At the interface of sensory and motor dysfunctions and Alzheimer's disease. Alzheimers Dement 11:70-98

Allard P, Alafuzoff I, Carlsson A, Eriksson K, Ericson E, Gottfries CG, Marcusson JO (1990) Loss of dopamine uptake sites labeled with [3H]GBR-12935 in Alzheimer's disease. Eur Neurol 30:181-185

Amin J, Paquet C, Baker A, Asuni AA, Love S, Holmes C, Hugon J, Nicoll JA, Boche D (2015) Effect of amyloid- $\beta(A \beta)$ immunization on hyperphosphorylated tau: a potential role for glycogen synthase kinase (GSK)-3 $\beta$. Neuropathol Appl Neurobiol 41:445-457

Amiri S, Haj-Mirzaian A, Momeny M, Amini-Khoei H, Rahimi-Balaei M, Poursaman S, Rastegar M, Nikoui V, Mokhtari T, GhaziKhansari M, Hosseini MJ (2017) Streptozotocin induced oxidative stress, innate immune system responses and behavioural abnormalities in male mice. Neuroscience 340:373-383

An Y, Varma VR, Varma S et al (2018) Evidence for brain glucose dysregulation in Alzheimer's disease. Alzheimers Dement 14:318-329

Angelova PR, Abramov AY (2016) Functional role of mitochondrial reactive oxygen species in physiology. Free Radic Biol Med 100:81-85

Anitha M, Abraham PM, Paulose CS (2012) Striatal dopamine receptors modulate the expression of insulin receptor, IGF-1 and GLUT-3 in diabetic rats: effect of pyridoxine treatment. Eur J PharmacolDec 696:54-61

Arluison M, Quignon M, Nguyen P, Thorens B, Leloup C, Penicaud L (2004) Distribution and anatomical localization of the glucose transporter 2 (GLUT2) in the adult rat brain-an immunohistochemical study. J Chem Neuroanat 28:117-136

Arora R, Deshmukh R (2017) Embelin attenuates intracerebroventricular streptozotocin-induced behavioral, biochemical, and neurochemical abnormalities in rats. Mol Neurobiol 54:6670-6680

Athauda D, Foltynie T (2016) The glucagon-like peptide 1 (GLP) receptor as a therapeutic target in Parkinson's disease: mechanisms of action. Drug Discov Today 21:802-818

Babic Perhoc A, Osmanovic Barilar J, Knezovic A, Farkas V, Bagaric R, Svarc A, Grünblatt E, Riederer P, Salkovic-Petrisic M (2019) Cognitive, behavioral and metabolic effects of oral galactose treatment in the transgenic $\operatorname{Tg} 2576$ mice. Neuropharmacology 148:50-67

Ballard C, Gauthier S, Corbett A, Brayne C, Aarsland D, Jones E (2011) Alzheimer's disease. Lancet 377:1019-1031

Barilar JO, Knezovic A, Grünblatt E, Riederer P, Salkovic-Petrisic M (2015) Nine-month follow-up of the insulin receptor signalling cascade in the brain of streptozotocin rat model of sporadic Alzheimer's disease. J Neural Transm (Vienna) 122:565-576

Becker B, Demirbas M, Johann S, Zendedel A, Beyer C, Clusmann H, Haas SJ, Wree A, Tan SKH, Kipp M (2018) Effect of intrastriatal 6-OHDA lesions on extrastriatal brain structures in the mouse. Mol Neurobiol 55:4240-4252

Biosa A, Outeiro TF, Bubacco L, Bisaglia M (2018) Diabetes mellitus as a risk factor for Parkinson's disease: a molecular point of view. Mol Neurobiol 55:8754-8763

Biswas J, Gupta S, Verma DK, Gupta P, Singh A, Tiwari S, Goswami P, Sharma S, Singh S (2018) Involvement of glucose related energy crisis and endoplasmic reticulum stress: insinuation of streptozotocin induced Alzheimer's like pathology. Cell Signal 42:211-226

Bloom GS, Lazo JS, Norambuena A (2018) Reduced brain insulin signaling: a seminal process in Alzheimer's disease pathogenesis. Neuropharmacology 136:192-195

Bolzán AD, Bianchi MS (2002) Genotoxicity of streptozotocin. Mutat Res. 512:121-134

Bonito-Oliva A, Pignatelli M, Spigolon G, Yoshitake T, Seiler S, Longo F et al (2014) Cognitive impairment and dentate gyrus 
synaptic dysfunction in experimental Parkinsonism. Biol Psychiatry 75:701-710

Bordey A, Sontheimer H (2000) Ion channel expression by astrocytes in situ: comparison of different CNS regions. Glia 30:27-38

Braak H, Del Tredici K, Rüb U, de Vos RA, Jansen Steur EN, Braak E (2003) Staging of brain pathology related to sporadic Parkinson's disease. Neurobiol Aging 24:197-211

Brooks DJ (2010) Examining Braak's hypothesis by imaging Parkinson's disease. Mov Disord 25:S83-88

Brownell AL, Canales K, Chen YI, Jenkins BG, Owen C, Livni E, Yu M, Cicchetti F, Sanchez-Pernaute R, Isacson O (2003) Mapping of brain function after MPTP-induced neurotoxicity in a primate Parkinson's disease model. Neuroimage 20:1064-1075

Budni J, Feijó DP, Batista-Silva H, Garcez ML, Mina F, BelletiniSantos T, Krasilchik LR, Luz AP, Schiavo GL, Quevedo J (2017) Lithium and memantine improve spatial memory impairment and neuroinflammation induced by $\beta$-amyloid $1-42$ oligomers in rats. Neurobiol Learn Mem 141:84-92

Burwinkel M, Lutzenberger M, Heppner FL, Schulz-Schaeffer W, Baier M (2018) Intravenous injection of beta-amyloid seeds promotes cerebral amyloid angiopathy (CAA). Acta Neuropathol Commun 6:23

Caballol N, Martí MJ, Tolosa E (2007) Cognitive dysfunction and dementia in Parkinson disease. Mov Disord 17:S358-366

Casteels C, Lauwers E, Bormans G, Baekelandt V, Van Laere K (2008) Metabolic-dopaminergic mapping of the 6-hydroxydopamine rat model for Parkinson's disease. Eur J Nucl Med Mol Imaging 35:124-134

Castro AA, Wiemes BP, Matheus FC, Lapa FR, Viola GG, Santos AR, Tasca CI, Prediger RD (2013) Atorvastatin improves cognitive, emotional and motor impairments induced by intranasal 1-methyl-4-phenyl-1,2,3,6-tetrahydropyridine (MPTP) administration in rats, an experimental model of Parkinson's disease. Brain Res 1513:103-116

Chen Z, Zhong C (2013) Decoding Alzheimer's disease from perturbed cerebral glucose metabolism: implications for diagnostic and therapeutic strategies. Prog Neurobiol 108:21-43

Chen HH, Chang PC, Chen C, Chan MH (2018a) Protective and therapeutic activity of honokiol in reversing motor deficits and neuronal degeneration in the mouse model of Parkinson's disease. Pharmacol Rep 70:668-676

Chen Y, Guo Z, Mao YF, Zheng T, Zhang B (2017) Intranasal insulin ameliorates cerebral hypometabolism, neuronal loss, and astrogliosis in streptozotocin-induced Alzheimer's rat model. Neurotox Res 33:716-724

Chen Y, Guo Z, Mao YF, Zheng T, Zhang B (2018b) Intranasal insulin ameliorates cerebral hypometabolism, neuronal loss, and astrogliosis in streptozotocin-induced Alzheimer's rat model. Neurotox Res 33:716-724

Churchill MJ, Pflibsen L, Sconce MD, Moore C, Kim K, Meshul CK (2017) Exercise in an animal model of Parkinson's disease: motor recovery but not restoration of the nigrostriatal pathway. Neuroscience 359:224-247

Cicchetti F, Brownell AL, Williams K, Chen YI, Livni E, Isacson O (2001) Neuroinflammation of the nigrostriatal pathway during progressive 6-OHDA dopamine degeneration in rats monitored by immunohistochemistry and PET imaging. Eur J Neurosci 15:991-998

Claxton A, Baker LD, Hanson A, Trittschuh EH, Cholerton B, Morgan A, Callaghan M, Arbuckle M, Behl C, Craft S (2015) Long acting intranasal insulin detemir improves cognition for adults with mild cognitive impairment or early-stage Alzheimer's disease dementia. J Alzheimers Dis. 45:1269-1270

Correia SC, Santos RX, Santos MS, Casadesus G, Lamanna JC, Perry G, Smith MA, Moreira PI (2013) Mitochondrial abnormalities in a streptozotocin-induced rat model of sporadic Alzheimer's disease. Curr Alzheimer Res 10:406-419

Costa G, Simola N, Morelli M (2014) MDMA administration during adolescence exacerbates MPTP-induced cognitive impairment and neuroinflammation in the hippocampus and prefrontal cortex. Psychopharmacology 231:4007-4018

Costa M, Bernardi J, Fiuza T, Costa L, Brandão R, Pereira ME (2016) $\mathrm{N}$-Acetylcysteine protects memory decline induced by streptozotocin in mice. Chem Biol Interact 253:10-17

Crabbé M, Van der Perren A, Bollaerts I, Kounelis S, Baekelandt V, Bormans G, Casteels C, Lieve Moons L, Van Laere K (2019) Increased $\mathrm{P} 2 \mathrm{X} 7$ receptor binding is associated with neuroinflammation in acute but not chronic rodent models for Parkinson's disease. Front Neurosci 13:799

Da Cunha C, Wietzikoski S, Wietzikoski EC, Miyoshi E, Ferro MM, Anselmo-Franci JA, Canteras NS (2003) Evidence for the substantia nigra pars compacta as an essential component of a memory system independent of the hippocampal memory system. Neurobiol Learn Mem 79:236-242

Da Cunha C, Silva MH, Wietzikoski S, Wietzikoski EC, Ferro MM, Kouzmine I, Canteras NS (2006) Place learning strategy of substantia nigra pars compacta-lesioned rats. Behav Neurosci 120:1279-1284

Datta I, Ganapathy K, Razdan R, Bhonde R (2018) Location and number of astrocytes determine dopaminergic neuron survival and function under 6-OHDA stress mediated through differential BDNF release. Mol Neurobiol 55:5505-5525

Davie CA (2008) A review of Parkinson's disease. Br Med Bull 86:109-127

de la Monte SM, Tong M (2014) Brain metabolic dysfunction at the core of Alzheimer's disease. Biochem Pharmacol 88:548-559

Defelice FG, Ferreira ST (2002) Physiopathological modulators of amyloid aggregation and novel pharmacological approaches in Alzheimer's disease. An Acad Bras Cienc 74:265-284

Deng Y, Li B, Liu Y, Iqbal K, Grundke-Iqbal I, Gong CX (2009) Dysregulation of insulin signaling, glucose transporters, $O$-GlcNAcylation, and phosphorylation of tau and neurofilaments in the brain: implication for Alzheimer's disease. Am J Pathol 175:2089-2098

Ding A, Nitsch R, Hoyer S (1992) Changes in brain monoaminergic neurotransmitter concentrations in rat after intracerebroventricular injection of streptozotocin. J Cereb Blood Flow Metab 12:103-109

Dos Santos JPA, Vizuete A, Hansen F, Biasibetti R, Gonçalves CA (2018) Early and persistent $O$-GlcNAc protein modification in the streptozotocin model of Alzheimer's disease. J Alzheimers Dis 61:237-249

Dwyer DS, Vannucci SJ, Simpson IA (2002) Expression, regulation, and functional role of glucose transporters (GLUTs) in brain. Int Rev Neurobiol 51:159-188

Eisele YS, Bolmont T, Heikenwalder M, Langer F, Jacobson LH, Yan ZX, Roth K, Aguzzi A, Staufenbiel M, Walker LC, Jucker M (2009) Induction of cerebral beta-amyloidosis: intracerebral versus systemic Abeta inoculation. Proc Natl Acad Sci USA 106:12926-21231

Eisele YS, Obermüller U, Heilbronner G, Baumann F, Kaeser SA, Wolburg H, Walker LC, Staufenbiel M, Heikenwalder M, Jucker M (2010) Peripherally applied Abeta-containing inoculates induce cerebral beta-amyloidosis. Science 330:980-982

Eisele YS, Fritschi SK, Hamaguchi T, Obermüller U, Füger P, Skodras A, Schäfer C, Odenthal J, Heikenwalder M, Staufenbiel M, Jucker M (2014) Multiple factors contribute to the peripheral induction of cerebral $\beta$-amyloidosis. J Neurosci 34:10264-10273

Eleazu CO, Eleazu KC, Chukwuma S, Essien UN (2013) Review of the mechanism of cell death resulting from streptozotocin challenge 
in experimental animals, its practical use and potential risk to humans. J Diabetes Metab Disord 12:60

Engelender S, Isacson O (2017) The threshold theory for Parkinson's disease. Trends Neurosci 40:4-14

Facchinetti R, Bronzuoli MR, Scuderi C (2018) An animal model of Alzheimer disease based on the intrahippocampal injection of amyloid $\beta$-peptide (1-42). Methods Mol Biol 1727:343-352

Falardeau P, Bédard PJ, Di Paolo T (1988) Relation between brain dopamine loss and D2 dopamine receptor density in MPTP monkeys. Neurosci Lett 86:225-229

Falquetto B, Tuppy M, Potje SR, Moreira TS, Antoniali C, Takakura AC (2017) Cardiovascular dysfunction associated with neurodegeneration in an experimental model of Parkinson's disease. Brain Res 1657:156-166

Femminella GD, Edison P (2014) Evaluation of neuroprotective effect of glucagon-like peptide 1 analogs using neuroimaging. Alzheimers Dement 10:S55-61

Feng XY, Yang J, Zhang X, Zhu J (2019) Gastrointestinal non-motor dysfunction in Parkinson's disease model rats with 6-hydroxydopamine. Physiol Res 68:295-303

Fernandez-Ruiz J, Doudet DJ, Aigner TG (1995) Long-term cognitive impairment in MPTP-treated rhesus monkeys. NeuroReport 7:102-104

Fifel K, Dkhissi-Benyahya O, Cooper HM (2013) Lack of long-term changes in circadian, locomotor, and cognitive functions in acute and chronic MPTP (1-methyl-4-phenyl-1,2,3,6-tetrahydropyridine) mouse models of Parkinson's disease. Chronobiol Int 30:741-755

Figlewicz DP, Evans SB, Murphy J, Hoen M, Baskin DG (2003) Expression of receptors for insulin and leptin in the ventral tegmental area/substantia nigra (VTA/SN) of the rat. Brain Res 964:107-115

Foffani G, Obeso JA (2018) A cortical pathogenic theory of Parkinson's disease. Neuron 99:1116-1128

Fulceri F, Biagioni F, Lenzi P, Falleni A, Gesi M, Ruggieri S, Fornai F (2006) Nigrostriatal damage with 6-OHDA. Cell 166:867-880

Gai W, Schott-Ohly P, Schulte IM, Walde S, Gleichmann H (2004) Differential target molecules for toxicity induced by streptozotocin and alloxan in pancreatic islets of mice in vitro. Exp Clin Endocrinol Diabetes 112:29-37

Garabadu D, Verma J (2019) Exendin-4 attenuates brain mitochondrial toxicity through PI3K/Akt dependent pathway in amyloid beta (1-42)-induced cognitive deficit rats. Neurochem Int 128:39-49

García-Cáceres C, Quarta C, Varela L, Gao Y, Gruber T, Legutko B, Jastroch M, Johansson P et al (2016) Astrocytic insulin signaling couples brain glucose uptake with nutrient availability. Cell 166:867-880

Garcia-Tornadú I, Perez-Millan MI, Recouvreux V, Ramirez MC, Luque G, Risso GS, Ornstein AM, Cristina C, Diaz-Torga G, Becu-Villalobos D (2010) New insights into the endocrine and metabolic roles of dopamine D2 receptors gained from the Drd2 mouse. Neuroendocrinology 92:207-214

Gerhart DZ, Leino RL, Borson ND, Taylor WE, Gronlund KM, McCall AL, Drewes LR (1995) Localization of glucose transporter GLUT 3 in brain: comparison of rodent and dog using speciesspecific carboxyl-terminal antisera. Neuroscience 66:237-246

Gibb WR, Lees AJ, Jenner P, Marsden CD (1986) The dopamine neurotoxin 1-methyl-4-phenyl-1,2,3,6-tetrahydropyridine (MPTP) produces histological lesions in the hypothalamus of the common marmoset. Neurosci Lett 65:79-83

Goes AT, Souza LC, Filho CB, Del Fabbro L, De Gomes MG, Boeira SP, Jesse CR (2014) Neuroprotective effects of swimming training in a mouse model of Parkinson's disease induced by 6-hydroxydopamine. Neuroscience 256:61-71

Goes ATR, Jesse CR, Antunes MS, Lobo Ladd FV, Lobo Ladd AAB, Luchese C, Paroul N, Boeira SP (2018) Protective role of chrysin on 6-hydroxydopamine-induced neurodegeneration a mouse model of Parkinson's disease: involvement of neuroinflammation and neurotrophins. Chem Biol Interact 279:111-120

Graham WC, Clarke CE, Boyce S, Sambrook MA, Crossman AR, Woodruff GN (1990) Autoradiographic studies in animal models of hemi-parkinsonism reveal dopamine D2 but not D1 receptor supersensitivity. II. Unilateral intra-carotid infusion of MPTP in the monkey (Macaca fascicularis). Brain Res 514:103-110

Gratwicke J, Jahanshahi M, Foltynie T (2018) Parkinson's disease dementia: a neural networks perspective. Brain 138:1454-1476

Grospe GM, Baker PM, Ragozzino ME (2018) Cognitive flexibility deficits following 6-OHDA lesions of the rat dorsomedial striatum. Neuroscience 374:80-90

Gruenblatt E, Salkovic-Petrisic M, Osmanovic J, Riederer P, Hoyer S (2007) Brain insulin system dysfunction in streptozotocin intracerebroventricularly treated rats generates hyperphosphorylated tau protein. J Neurochem 101:757-770

Guerra de Souza AC, Gonçalves CL, de Souza V, Hartwig JM, Farina M, Prediger RD (2018) Agmatine attenuates depressive-like behavior and hippocampal oxidative stress following amyloid $\beta$ (A $\beta 1-40)$ administration in mice. Behav Brain Res 353:51-56

Gupta S, Yadav K, Mantri SS, Singhal NK, Ganesh S, Sandhir R (2018) Evidence for compromised insulin signaling and neuronal vulnerability in experimental model of sporadic Alzheimer's disease. Mol Neurobiol 55:8916-8935

Haddadi R, Poursina M, Zeraati F, Nadi F (2018) Gastrodin microinjection suppresses 6-OHDA-induced motor impairments in parkinsonian rats: insights into oxidative balance and microglial activation in SNc. Inflammopharmacology 26:1305-1316

Haga H, Matsuo K, Yabuki Y, Zhang C, Han F, Fukunaga K (2019) Enhancement of ATP production ameliorates motor and cognitive impairments in a mouse model of MPTP-induced Parkinson's disease. Neurochem Int 129:104492

Han Z, Tian R, Ren P, Zhou W, Wang P, Luo M, Jin S (2018) Parkinson's disease and Alzheimer's disease: a Mendelian randomization study. BMC Med Genet 19:215

Harkany T, Hortobágyi T, Sasvári M, Kónya C, Penke B, Luiten PG, Nyakas C (1999) Neuroprotective approaches in experimental models of beta-amyloid neurotoxicity: relevance to Alzheimer's disease. Prog Neuropsychopharmacol Biol Psychiatry 23:963-1008

Heo JH, Lee SR, Lee ST, Lee KM, Oh JH, Jang DP, Chang KT, Cho ZH (2011) Spatial distribution of glucose hypometabolism induced by intracerebroventricular streptozotocin in monkeys. J Alzheimers Dis 25:517-523

Hill JM, Lesniak MA, Pert CB, Roth J (1986) Autoradiographic localization of insulin receptors in rat brain: prominence in olfactory and limbic areas. Neuroscience 17:1127-1138

Horita KT, Kobayashi M, Mori A, Jenner P, Kanda T (2015) Effects of the adenosine A2A antagonist istradefylline on cognitive performance in rats with a 6-OHDA lesion in prefrontal cortex. Psychopharmacology 230:345-352

Hoyer S (2004) Glucose metabolism and insulin receptor signal transduction in Alzheimer disease. Eur J Pharmacol 490:115-125

Hu D, Cao Y, He R, Han N, Liu Z, Miao L, Yin J (2012) Schizandrin, an antioxidant lignan from Schisandra chinensis, ameliorates A 31 -42-induced memory impairment in mice. Oxid Med Cell Longev 2012:721721

Hu M, Li F, Wang W (2018) Vitexin protects dopaminergic neurons in MPTP-induced Parkinson's disease through PI3K/Akt signaling pathway. Drug Des Devel Ther 12:565-573

Isaev NK, Genrikhs EE, Voronkov DN, Kapkaeva MR, Stelmashook EV (2018) Streptozotocin toxicity in vitro depends on maturity of neurons. Toxicol Appl Pharmacol 348:99-104

Jafari A, Noursadeghi E, Khodagholi F, Saghiri R, Sauve R, Aliaghaei A, Eliassi A (2015) Brain mitochondrial ATP-insensitive large 
conductance $\mathrm{Ca}^{2+}$-activated $\mathrm{K}^{+}$channel properties are altered in a rat model of amyloid- $\beta$ neurotoxicity. Exp Neurol 269:8-16

Jang DP, Min HK, Lee SY, Kim IY, Park HW, Im YH, Lee S, Sim J, Kim YB, Paek SH, Cho ZH (2012) Functional neuroimaging of the 6-OHDA lesion rat model of Parkinson's disease. Neurosci Lett 513:187-192

Javed H, Vaibhav K, Ahmed ME, Khan A, Tabassum R, Islam F, Safhi MM, Islam F (2015) Effect of hesperidin on neurobehavioral, neuroinflammation, oxidative stress and lipid alteration in intracerebroventricular streptozotocin induced cognitive impairment in mice. J Neurol Sci 348:51-59

Javitch JA, D’Amato RJ, Strittmatter SM, Snyder SH (1985) Parkinsonism-inducing neurotoxin, $N$-methyl-4-phenyl-1,2,3,6-tetrahydropyridine: uptake of the metabolite $N$-methyl-4-phenylpyridine by dopamine neurons explains selective toxicity. Proc Natl Acad Sci USA 82:2173-2177

Jayant S, Sharma BM, Sharma B (2016) Protective effect of transient receptor potential vanilloid subtype 1 (TRPV1) modulator, against behavioral, biochemical and structural damage in experimental models of Alzheimer's disease. Brain Res 1642:397-408

Jellinger KA (2019) Neuropathology and pathogenesis of extrapyramidal movement disorders: a critical update-I. Hypokinetic-rigid movement disorders. J Neural Transm (Vienna) 126:933-995

Jing H, Wang S, Wang M, Fu W, Zhang C, Xu D (2017) Isobavachalcone attenuates MPTP-induced Parkinson's disease in mice by inhibition of microglial activation through NF- $\mathrm{KB}$ pathway. PLoS ONE 12:e0169560

Jurcovicova J (2014) Glucose transport in brain-effect of inflammation. Endocr Regul 48:35-48

Kamat PK (2015) Streptozotocin induced Alzheimer's disease like changes and the underlying neural degeneration and regeneration mechanism. Neural Regen Res 10:1050-1052

Kang L, Routh VH, Kuzhikandathil EV, Gaspers LD, Levin BE (2004) Physiological and molecular characteristics of rat hypothalamic ventromedial nucleus glucosensing neurons. Diabetes 53:549-559

Kaundal M, Deshmukh R, Akhtar M (2018) Protective effect of betulinic acid against intracerebroventricular streptozotocin induced cognitive impairment and neuronal damage in rats: possible neurotransmitters and neuroinflammatory mechanism. Pharmacol Rep 70:540-548

Kleinridders A, Cai W, Cappellucci L, Ghazarian A, Collins WR, Vienberg SG, Pothos EN, Kahn CR (2015) Insulin resistance in brain alters dopamine turnover and causes behavioral disorders. Proc Natl Acad Sci USA 11:3463-3468

Knezovic A, Osmanovic Barilar J, Babic A, Bagaric R, Farkas V, Riederer P, Salkovic-Petrisic M (2018) Glucagon-like peptide-1 mediates effects of oral galactose in streptozotocin-induced rat model of sporadic Alzheimer's disease. Neuropharmacology 135:48-62

Knezovic A, Osmanovic-Barilar J, Curlin M, Hof PR, Simic G, Riederer P, Salkovic-Petrisic M (2015) Staging of cognitive deficits and neuropathological and ultrastructural changes in streptozotocin-induced rat model of Alzheimer's disease. J Neural Transm (Vienna) 122:577-592

Knezovic A, Loncar A, Homolak J, Smailovic U, Osmanovic Barilar J, Ganoci L, Bozina N, Riederer P, Salkovic-Petrisic M (2017) Rat brain glucose transporter-2, insulin receptor and glial expression are acute targets of intracerebroventricular streptozotocin: risk factors for sporadic Alzheimer's disease? J Neural Transm (Vienna) 124:695-708

Ko WKD, Camus SM, Li Q, Yang J, McGuire S, Pioli EY, Bezard E (2016) An evaluation of istradefylline treatment on Parkinsonian motor and cognitive deficits in 1-methyl-4-phenyl-1,2,3,6tetrahydropyridine (MPTP)-treated macaque models. Neuropharmacology 110:48-58
Kraska A, Santin MD, Dorieux O, Joseph-Mathurin N, Bourrin E, Petit F, Jan C, Chaigneau M, Hantraye P, Lestage P, Dhenain M (2012) In vivo cross-sectional characterization of cerebral alterations induced by intracerebroventricular administration of streptozotocin. PLoS ONE 7:e46196

Krishnamoorthy A, Sevanan M, Mani S, Balu M, Balaji S, Ramajayan P (2019) Chrysin restores MPTP induced neuroinflammation, oxidative stress and neurotrophic factors in an acute Parkinson's disease mouse model. Neurosci Lett 709:134382

Kumar A, Singh N (2017) Inhibitor of phosphodiestearse-4 improves memory deficits, oxidative stress, neuroinflammation and neuropathological alterations in mouse models of dementia of Alzheimer's Type. Biomed Pharmacother 88:698-707

Kumar M, Bansal N (2018) Ellagic acid prevents dementia through modulation of PI3-kinase-endothelial nitric oxide synthase signalling in streptozotocin-treated rats. Naunyn Schmiedebergs Arch Pharmacol 391:987-1001

Lacković Z, Salković M (1990) Streptozotocin and alloxan produce alterations in rat brain monoamines independently of pancreatic beta cells destruction. Life Sci 46:49-54

Lagrue E, Abe H, Lavanya M, Touhami J, Bodard S, Chalon S, Battini JL, Sitbon M, Castelnau P (2010) Regional characterization of energy metabolism in the brain of normal and MPTP-intoxicated mice using new markers of glucose and phosphate transport. J Biomed Sci 17:91

Lana E, Khanbolouki M, Degavre C, Samuelsson EB, Åkesson E, Winblad B, Alici E, Lithner CU, Behbahani H (2017) Perforin promotes amyloid beta internalisation in neurons. Mol Neurobiol 54:874-887

Landrigan PJ, Sonawane B, Butler RN, Trasande L, Callan R, Droller D (2005) Early environmental origins of neurodegenerative disease in later life. Environ Health Perspect 113:1230-1233

Lau YS, Meredith GE (2003) From drugs of abuse to parkinsonism. The MPTP mouse model of Parkinson's disease. Methods Mol Med 79:103-116

Lee Y, Kim YH, Park SJ, Huh JW, Kim SH, Kim SU, Kim JS, Jeong KJ, Lee KM, Hong Y, Lee SR, Chang KT (2014) Insulin/IGF signaling-related gene expression in the brain of a sporadic Alzheimer's disease monkey model induced by intracerebroventricular injection of streptozotocin. J Alzheimers Dis. 38:251-267

Lester-Coll N, Rivera EJ, Soscia SJ, Doiron K, Wands JR, de la Monte SM (2006) Intracerebral streptozotocin model of type 3 diabetes: relevance to sporadic Alzheimer's disease. J Alzheimers Dis 9:13-33

Levin J (2019) Parkinsonism in genetic and sporadic Alzheimer's disease. Int Rev Neurobiol 149:237-247

Liu AK, Chang RC, Pearce RK, Gentleman SM (2015) Nucleus basalis of Meynert revisited: anatomy, history and differential involvement in Alzheimer's and Parkinson's disease. Acta Neuropathol 129:527-540

Lim HS, Kim JS, Moon BC, Ryu SM, Lee J, Park G (2019) Batryticatus bombyx protects dopaminergic neurons against MPTPinduced neurotoxicity by inhibiting oxidative damage. Antioxidants (Basel) 8(12):E574

Liu Y, Liu F, Iqbal K, Grundke-Iqbal K, Gong CX (2008) Decreased glucose transporters correlate to abnormal hyperphosphorylation of tau in Alzheimer disease. FEBS Lett 582:359-364

Liu A, Zhao X, Li H, Liu Z, Liu B, Mao X, Guo L, Bi K, Jia Y (2014) 5-Hydroxymethylfurfural, an antioxidant agent from Alpinia oxyphylla Miq. improves cognitive impairment in $\mathrm{A} \beta$ 1-42 mouse model of Alzheimer's disease. Int Immunopharmacol 23:719-725

Liu Y, Liu F, Grundke-Iqbal I, Iqbal K, Gong CX (2009) Brain glucose transporters, $O$-GlcNAcylation and phosphorylation of tau in diabetes and Alzheimer disease. J Neurochem 111:242-249 
Liu Y, Geng L, Zhang J, Wang J, Zhang Q, Duan D, Zhang Q (2018) Oligo-porphyran ameliorates neurobehavioral deficits in parkinsonian mice by regulating the PI3K/Akt/Bcl-2 pathway. Mar Drugs 16:3

Ma D, Shuler JM, Raider KD, Rogers RS, Wheatley JL, Geiger PC, Stanford JA (2015) Effects of discontinuing a high-fat diet on mitochondrial proteins and 6-hydroxydopamine-induced dopamine depletion in rats. Brain Res 1613:49-58

Ma Y, Zhan M, OuYang L, Li Y, Chen S, Wu J, Chen J, Luo C, Lei W (2014) The effects of unilateral 6-OHDA lesion in medial forebrain bundle on the motor, cognitive dysfunctions and vulnerability of different striatal interneuron types in rats. Behav Brain Res 266:37-45

Maione F, Piccolo M, De Vita S, Chini MG, Cristiano C, De Caro C, Lippiello P, Miniaci MC, Santamaria R, Irace C, De Feo V, Calignano A, Mascolo N, Bifulco G (2017) Down regulation of pro-inflammatory pathways by tanshinone IIA and cryptotanshinone in a non-genetic mouse model of Alzheimer's disease. Pharmacol Res 129:482-490

Majkutewicz I, Kurowska E, Podlacha M, Myślińska D, Grembecka B, Ruciński J, Plucińska K, Jerzemowska G, Wrona D (2016) Dimethyl fumarate attenuates intracerebroventricular streptozotocin-induced spatial memory impairment and hippocampal neurodegeneration in rats. Behav Brain Res 308:24-37

Mansur RB, Lee Y, Subramaniapillai M, Cha DS, Brietzke E, McIntyre RS (2019) Parsing metabolic heterogeneity in mood disorders: a hypothesis-driven cluster analysis of glucose and insulin abnormalities. Bipolar Disord. https://doi.org/10.1111/bdi.12826 (epub ahead of print)

Mantych GJ, James DE, Chung HD, Devaskar SU (1992) Cellular localization and characterization of Glut 3 glucose transporter isoform in human brain. Endocrinology 131:1270-1278

Maragakis NJ, Rothstein JD (2006) Mechanisms of disease: astrocytes in neurodegenerative disease. Nat Clin Pract Neurol 2:679-689

Martinez A, Perez DI, Gil C (2013) Lessons learnt from glycogen synthase kinase 3 inhibitors development for Alzheimer's disease. Curr Top Med Chem 13:1808-1819

Mori MA, Delattre AM, Carabelli B et al (2018) Neuroprotective effect of omega- 3 polyunsaturated fatty acids in the 6-OHDA model of Parkinson's disease is mediated by a reduction of inducible nitric oxide synthase. Nutr Neurosci. 21:341-351

Moriguchi S, Yabuki Y, Fukunaga K (2012) Reduced calcium/calmodulin-dependent protein kinase II activity in the hippocampus is associated with impaired cognitive function in MPTP-treated mice. J Neurochem 120:541-551

Morris JK, Zhang H, Gupte AA, Bomhoff GL, Stanford JA, Geiger PC (2008) Measures of striatal insulin resistance in a 6-hydroxydopamine model of Parkinson's disease. Brain Res. 1240:185-195

Morroni F, Sita G, Tarozzi A, Rimondini R, Hrelia P (2016) Early effects of A $\beta 1-42$ oligomers injection in mice: involvement of PI3K/Akt/GSK3 and MAPK/ERK1/2 pathways. Behav Brain Res 314:106-115

Motzko-Soares ACP, Vizin RCL, Martins TMS, Hungaro ARO, Sato JR, Almeida MC, Carrettiero DC (2018) Thermoregulatory profile of neurodegeneration-induced dementia of the Alzheimer's type using intracerebroventricular streptozotocin in rats. Acta Physiol (Oxf) 224:e13084

Mukhin VN, Sizov VV, Pavlov KI, Klimenko VM (2019) $\beta$-Amyloid 25-35 suppresses the secretory activity of the dopaminergic system in the rat brain. Neurosci Behav Physiol 49:816-821

Narayan P, Holmström KM, Kim DH, Whitcomb DJ, Wilson MR, St George-Hyslop P, Wood NW, Dobson CM, Cho K, Abramov AY, Klenerman D (2014) Rare individual amyloid- $\beta$ oligomers act on astrocytes to initiate neuronal damage. Biochemistry 53:2442-2453
Nassar SZ, Badae NM, Issa YA (2018) Effect of amylin on memory and central insulin resistance in a rat model of Alzheimer's disease. Arch Physiol Biochem 17:1-9

Nezhadi A, Sheibani V, Esmaeilpour K, Shabani M, Esmaeili-Mahani S (2016) Neurosteroid allopregnanolone attenuates cognitive dysfunctions in 6-OHDA-induced rat model of Parkinson's disease. Behav Brain Res 305:258-264

O'Keeffe ST, Kazeem H, Philpott RM, Playfer JR, Gosney M, Lye M (1996) Gait disturbance in Alzheimer's disease: a clinical study. Age Ageing 25:313-316

Osmanovic J, Plaschke K, Salkovic-Petrisic M, Grünblatt E, Riederer P, Hoyer S (2010) Chronic exogenous corticosterone administration generates an insulin-resistant brain state in rats. Stress 13:123-131

Ozkay UD, Can OD, Ozkay Y, Oztürk Y (2012) Effect of benzothiazole/piperazine derivatives on intracerebroventricular streptozotocin-induced cognitive deficits. Pharmacol Rep 64:834-847

Pandey D, Banerjee S, Basu M, Mishra N (2016) Memory enhancement by Tamoxifen on amyloidosis mouse model. Horm Behav 79:70-73

Pearson-Leary J, McNay EC (2012a) Intrahippocampal administration of amyloid- $\beta(1-42)$ oligomers acutely impairs spatial working memory, insulin signaling, and hippocampal metabolism. J Alzheimers Dis 30:413-422

Pellegrini C, Fornai M, Colucci R, Tirotta E, Blandini F, Levandis G, Cerri S, Segnani C, Ippolito C, Bernardini N, Cseri K, Blandizzi C, Haskó G, Antonioli L (2016) Alteration of colonic excitatory tachykininergic motility and enteric inflammation following dopaminergic nigrostriatal neurodegeneration. J Neuroinflamm 13:146

Peng S, Ma Y, Flores J, Cornfeldt M, Mitrovic B, Eidelberg D, Doudet JD (2016b) Modulation of abnormal metabolic brain networks by experimental therapies in a nonhuman primate model of parkinson disease: an application to human retinal pigment epithelial cell implantation. J Nucl Med 57:1591-1598

Pérez V, Marin C, Rubio A, Aguilar E, Barbanoj M, Kulisevsky J (2009) Effect of the additional noradrenergic neurodegeneration to 6-OHDA-lesioned rats in levodopa-induced dyskinesias and in cognitive disturbances. J Neural Transm (Vienna) 116:1257-1266

Pinessi L, Rainero I, De Gennaro T, Gentile S, Portaleone P, Bergamasco B (1987) Biogenic amines in cerebrospinal fluid and plasma of patients with dementia of Alzheimer type. Funct Neurol 2:51-58

Pizzolato G, Chierichetti F, Fabbri M, Cagnin A, Dam M, Ferlin G, Battistin L (1996) Reduced striatal dopamine receptors in Alzheimer's disease: single photon emission tomography study with the D2 tracer [123I]-IBZM. Neurology 47:1065-1068

Plum L, Schubert M, Brüning JC (2005) The role of insulin receptor signaling in the brain. Trends Endocrinol Metab 16:59-65

Prediger RD, Batista LC, Medeiros R, Pandolfo P, Florio JC, Takahashi RN (2006) The risk is in the air: intranasal administration of MPTP to rats reproducing clinical features of Parkinson's disease. Exp Neurol 202:391-403

Przedborski S, Jackson-Lewis V, Djaldetti R, Liberatore G, Vila M, Vukosavic S, Almer G (2000) The parkinsonian toxin MPTP: action and mechanism. Restor Neurol Neurosci 16:135-142

Puchades M, Sogn CJ, Maehlen J, Bergersen LH, Gundersen V (2013) Unaltered lactate and glucose transporter levels in the MPTP mouse model of Parkinson's disease. J Parkinsons Dis 3:371-385

Rabie MA, Abd El Fattah MA, Nassar NN, El-Abhar HS, Abdallah DM (2018) Angiotensin 1-7 ameliorates 6-hydroxydopamine lesions in hemiparkinsonian rats through activation of MAS receptor/ $\mathrm{PI} 3 \mathrm{~K} / \mathrm{Akt} / \mathrm{BDNF}$ pathway and inhibition of angiotensin II type-1 receptor/NF- $\mathrm{kB}$ axis. Biochem Pharmacol 151:126-134 
Rai SN, Dilnashin H, Birla H, Singh SS, Zahra W, Rathore AS, Singh BK, Singh SP (2019) The role of PI3K/Akt and ERK in neurodegenerative disorders. Neurotox Res 35:775-795

Rajasekar N, Dwivedi S, Nath C, Hanif K, Shukla R (2014) Protection of streptozotocin induced insulin receptor dysfunction, neuroinflammation and amyloidogenesis in astrocytes by insulin. Neuropharmacology 86:337-352

Ramírez-García G, Palafox-Sánchez V, Limón ID (2015) Nitrosative and cognitive effects of chronic L-DOPA administration in rats with intra-nigral 6-OHDA lesion. Neuroscience 290:492-508

Razavinasab M, Shamsizadeh A, Shabani M, Nazeri M, Allahtavakoli M, Asadi-Shekaari M, Esmaeli-Mahani S, Sheibani V (2013) Pharmacological blockade of TRPV1 receptors modulates the effects of 6-OHDA on motor and cognitive functions in a rat model of Parkinson's disease. Fundam Clin Pharmacol 27:632-640

Riederer P, Berg D, Casadei N, Cheng F, Classen J, Dresel C et al (2019) $\alpha$-Synuclein in Parkinson's disease: causal or bystander? J Neural Transm (Vienna) 126:815-840

Rodrigues L, Wartchow KM, Suardi LZ, Federhen BC, Selistre NG, Gonçalves CA (2019) Streptozotocin causes acute responses on hippocampal S100B and BDNF proteins linked to glucose metabolism alterations. Neurochem Int 128:85-93

Russo I, Caracciolo L, Tweedie D, Choi SH, Greig NH, Barlati S, Bosetti F (2012) 3,6'-Dithiothalidomide, a new TNF- $\alpha$ synthesis inhibitor, attenuates the effect of A $\beta 1-42$ intracerebroventricular injection on hippocampal neurogenesis and memory deficit. J Neurochem 122:1181-1192

Saab AS, Neumeyer A, Jahn HM, Cupido A, Šimek AA, Boele HJ, Scheller A, Le Meur K, Götz M, Monyer H, Sprengel R, Rubio ME, Deitmer JW, De Zeeuw CI, Kirchhoff F (2012) Bergmann glial AMPA receptors are required for fine motor coordination. Science 337:749-753

Salković M, Sabolić I, Lacković Z (1995) Striatal dopaminergic D1 and D2 receptors after intracerebroventricular application of alloxan and streptozocin in rat. J Neural Transm Gen Sect 100:137-145

Salkovic-Petrisic M, Tribl F, Schmidt M, Hoyer S, Riederer P (2006) Alzheimer-like changes in protein kinase $\mathrm{B}$ and glycogen synthase kinase- 3 in rat frontal cortex and hippocampus after damage to the insulin signalling pathway. J Neurochem 96:1005-1015

Salkovic-Petrisic M, Osmanovic J, Grünblatt E, Riederer P, Hoyer S (2009) Modeling sporadic Alzheimer's disease: the insulin resistant brain state generates multiple long-term morphobiological abnormalities including hyperphosphorylated tau protein and amyloid-beta. J Alzheimers Dis 18:729-750

Salkovic-Petrisic M, Osmanovic-Barilar J, Knezovic A, Hoyer S, Mosetter K, Reutter W (2014) Long-term oral galactose treatment prevents cognitive deficits in male Wistar rats treated intracerebroventricularly with streptozotocin. Neuropharmacology $77: 68-80$

Salković-Petrisić M, Lacković Z (2003) Intracerebroventricular administration of betacytotoxics alters expression of brain monoamine transporter genes. J Neural Transm (Vienna) 110:15-29

Sandyk R, Iacono RP, Kay SR (1990) The hypothalamus in MPTPinduced Parkinsonism. Ital J Neurol Sci 20:20

Santiago JA, Potashkin JA (2013) Shared dysregulated pathways lead to Parkinson's disease and diabetes. Trends Mol Med 11(4):367-372

Sarkar S, Chigurupati S, Raymick J, Mann D, Bowyer JF, Schmitt T, Beger RD, Hanig JP, Schmued LC, Paule MG (2014) Neuroprotective effect of the chemical chaperone, trehalose in a chronic MPTP-induced Parkinson's disease mouse model. Neurotoxicology 44:250-262

Schechter R, Holtzclaw L, Sadiq F, Kahn A, Devaskar S (1988) Insulin synthesis by isolated rabbit neurons. Endocrinology 123:505-513
Schelp AO, Mendes-Chiloff CL, Paduan VC, Corrente JE, Vieira A, Marchette JCN, de Souza JT, Luvizuto GJ, Nogueira CR, Bazan R (2017) Amnestic dementia impairment in Parkinson's disease: the role of body composition, ageing and insulin resistance. Clin Nutr ESPEN 20:47-51

Schmid S, Jungwirth B, Gehlert V, Blobner M, Schneider G, Kratzer S, Kellermann K, Rammes G (2017) Intracerebroventricular injection of beta-amyloid in mice is associated with long-term cognitive impairment in the modified hole-board test. Behav Brain Res 324:15-20

Schnedl WJ, Ferber S, Johnson JH, Newgard CB (1994) STZ transport and cytotoxicity. Specific enhancement in GLUT2-expressing cells. Diabetes 43:1326-1333

Schulingkamp RJ, Pagano TC, Hung D, Raffa RB (2000) Insulin receptors and insulin action in the brain: review and clinical implications. Neurosci Biobehav Rev 24:855-872

Shonesy BC, Thiruchelvam K, Parameshwaran K, Rahman EA, Karuppagounder SS, Huggins KW, Pinkert CA, Amin R, Dhanasekaran M, Suppiramaniam V (2012) Central insulin resistance and synaptic dysfunction in intracerebroventricular-streptozotocin injected rodents. Neurobiol Aging 33:430.e5-18

Shyu WC, Li KW, Peng HF, Lin SZ, Liu RS, Wang HJ, Su CY, Lee YJ, Li H (2009) Induction of GAP-43 modulates neuroplasticity in PBSC (CD34+) implanted-Parkinson's model. J Neurosci Res 87:2020-2033

Silva MD, Glaus C, Hesterman JY, Hoppin J, Puppa GH, Kazules T, Orcutt KM, Germino M, Immke D, Miller S (2013) Regional, kinetic [(18)F]FDG PET imaging of a unilateral Parkinsonian animal model. Am J Nucl Med Mol Imaging 3:129-141

Simpson IA, Dwyer D, Malide D, Moley KH, Travis A, Vannucci SJ (2008) The facilitative glucose transporter GLUT3: 20 years of distinction. Am J Physiol Endocrinol Metab 295:E242-253

Singh S, Kumar P (2017) Neuroprotective potential of curcumin in combination with piperine against 6-hydroxy dopamine induced motor deficit and neurochemical alterations in rats. Inflammopharmacology 25:69-79

Solesio MA, Prime TA, Logan A, Murphy MP, Arroyo-Jimenez MM, Jordán J, Galindo MF (2013) The mitochondria-targeted antioxidant MitoQ reduces aspects of mitochondrial fission in the 6-OHDA cell model of Parkinson's disease. BBA Mol Basis Disease 1832:174-182

Sriram K, Pai KS, Boyd MR, Ravindranath V (1997) Evidence for generation of oxidative stress in brain by MPTP: in vitro and in vivo studies in mice. Brain Res 749:44-52

Storch A, Ludolph AC, Schwarz J (2004) Dopamine transporter: involvement in selective dopaminergic neurotoxicity and degeneration. J Neural Transm 111:1267-1286

Storga D, Vrecko K, Birkmayer JG, Reibnegger G (1996) Monoaminergic neurotransmitters, their precursors and metabolites in brains of Alzheimer patients. Neurosci Lett 203:29-32

Stouffer MA, Woods CA, Patel JC, Lee CR, Witkovsky P, Bao L, Machold RP, Jones KT, de Vaca SC, Reith ME, Carr KD, Rice ME (2015) Insulin enhances striatal dopamine release by activating cholinergic interneurons and thereby signals reward. Nat Commun 6:8543

Sun P, Ortega G, Tan Y, Hua Q, Riederer PF, Deckert J, Schmitt-Böhrer AG (2018) Streptozotocin impairs proliferation and differentiation of adult hippocampal neural stem cells in vitro-correlation with alterations in the expression of proteins associated with the insulin system. Front Aging Neurosci 10:145

Szkudelski T (2001) The mechanism of alloxan and streptozotocin action in B cells of the rat pancreas. Physiol Res 50:537-546

Tanji H, Araki T, Nagasawa H, Itoyama Y (1999) Differential vulnerability of dopamine receptors in the mouse brain treated with MPTP. Brain Res 824:224-231 
Thornton E, Vink R (2012) Treatment with a substance P receptor antagonist is neuroprotective in the intrastriatal 6-hydroxydopamine model of early Parkinson's disease. PLoS ONE 7:e34138

Tieu K (2011) A guide to neurotoxic animal models of Parkinson's disease. Cold Spring Harb Perspect Med 1:a009316

Tong M, Neusner A, Longato L, Lawton M, Wands JR, de la Monte SM (2009) Nitrosamine exposure causes insulin resistance diseases: relevance to type 2 diabetes mellitus, non-alcoholic steatohepatitis, and Alzheimer's disease. J Alzheimers Dis 17:827-844

Trabace L, Kendrick KM, Castrignanò S, Colaianna M, De Giorgi A, Schiavone S, Lanni C, Cuomo V, Govoni S (2007) Soluble amyloid beta1-42 reduces dopamine levels in rat prefrontal cortex: relationship to nitric oxide. Neuroscience 147:652-663

Verghese PB, Castellano JM, Garai K, Wang Y, Jiang H, Shah A, Bu G, Frieden C, Holtzman DM (2013) ApoE influences amyloid- $\beta$ $(\mathrm{A} \beta$ ) clearance despite minimal apoE/A $\beta$ association in physiological conditions. Proc Natl Acad Sci USA 110:E1807-1816

Vezoli J, Fifel K, Leviel V, Dehay C, Kennedy H, Cooper HM, Gronfier C, Procyk E (2011) Early presymptomatic and long-term changes of rest activity cycles and cognitive behavior in a MPTP-monkey model of Parkinson's disease. PLoS ONE 6:e23952

Vučković MG, Li Q, Fisher B, Nacca A, Leahy RM, Walsh JP, Mukherjee J, Williams C, Jakowec MW, Petzinger GME (2010) Exercise elevates dopamine D2 receptor in a mouse model of Parkinson's disease: in vivo imaging with $\left[{ }^{18} \mathrm{~F}\right]$ fallypride. Mov Disord 25:2777-2784

Walsh S, Finn DP, Dowd E (2011) Time-course of nigrostriatal neurodegeneration and neuroinflammation in the 6-hydroxydopamine induced axonal and terminal lesion models of Parkinson's disease in the rat. Neuroscience 175:251-261

Wang C, Cai Z, Wang W, Wei M, Kou D, Li T, Yang Z, Guo H, Le W, Li S (2019) Piperine attenuates cognitive impairment in an experimental mouse model of sporadic Alzheimer's disease. J Nutr Biochem 70:147-155

Wang D, Liu L, Li S, Wang C (2018a) Effects of paeoniflorin on neurobehavior, oxidative stress, brain insulin signaling, and synaptic alterations in intracerebroventricular streptozotocin-induced cognitive impairment in mice. Physiol Behav 191:12-20

Wang H, Wang R, Zhao Z, Ji Z, Xu S, Holscher C (2009) Coexistences of insulin signaling-related proteins and choline acetyltransferase in neurons. Brain Res 1249:237-243

Wang Y, Yu X, Zhang P, Ma Y, Wang L, Xu H, Sui D (2018b) Neuroprotective effects of pramipexole transdermal patch in the MPTPinduced mouse model of Parkinson's disease. J Pharmacol Sci 138:31-37

Wei J, Yang F, Gong C, Shi X, Wang G (2019) Protective effect of daidzein against streptozotocin-induced Alzheimer's disease via improving cognitive dysfunction and oxidative stress in rat model. J Biochem Mol Toxicol 21:e22319

Weihmuller FB, Bruno JP, Neff NH, Hadjiconstantinou M (1990) Dopamine receptor plasticity following MPTP-induced nigrostriatal lesions in the mouse. Eur J Pharmacol 1180:369-372

Wesén E, Jeffries GDM, Matson Dzebo M, Esbjörner EK (2017) Endocytic uptake of monomeric amyloid- $\beta$ peptides is clathrin- and dynamin-independent and results in selective accumulation of A $\beta(1-42)$ compared to A $\beta(1-40)$. Sci Rep 7:2021

Wilcox BJ, Matsumoto AM, Dorsa DM, Baskin DG (1989) Reduction of insulin binding in the arcuate nucleus of the rat hypothalamus after 6-hydroxydopamine treatment. Brain Res 500:149-155

Woiciechowsky C, Guilarte TR, May CH, Vesper J, Wagner HN Jr, Vogel S (1995) Intrastriatal dopamine infusion reverses compensatory increases in D2-dopamine receptors in the 6-OHDA lesioned rat. Neurodegeneration 4:161-169

Wu KL, Hung CY, Chan JY, Wu CW (2014) An increase in adenosine5 '-triphosphate (ATP) content in rostral ventrolateral medulla is engaged in the high fructose diet-induced hypertension. $\mathrm{J}$ Biomed Sci 27:21-28

Wu Y, Shang Y, Sun S, Liang H, Liu R (2007) Erythropoietin prevents PC12 cells from 1-methyl-4-phenylpyridinium ion-induced apoptosis via the Akt/GSK-3beta/caspase-3 mediated signaling pathway. Apoptosis 12:1365-1375

Xu L, Sapolsky RM, Giffard RG (2001) Differential sensitivity of murine astrocytes and neurons from different brain regions to injury. Exp Neurol 169:416-424

Xu M, Zhang HL (2011) Death and survival of neuronal and astrocytic cells in ischemic brain injury: a role of autophagy. Acta Pharmacol Sin 32:1089-1099

Xu M, Dong Y, Wan S, Yan T, Cao J, Wu L, Bi K, Jia Y (2016) Schisantherin B ameliorates A $\beta 1$-42-induced cognitive decline via restoration of GLT-1 in a mouse model of Alzheimer's disease. Physiol Behav 167:265-273

Yabuki Y, Ohizumi Y, Yokosuka A, Mimaki Y, Fukunaga K (2014) Nobiletin treatment improves motor and cognitive deficits seen in MPTP-induced Parkinson model mice. Neuroscience 259:126-141

Yan JJ, Kim DH, Moon YS, Jung JS, Ahn EM, Baek NI, Song DK (2004) Protection against beta-amyloid peptide-induced memory impairment with long-term administration of extract of Angelica gigas or decursinol in mice. Prog Neuropsychopharmacol Biol Psychiatry 28:25-30

Yang JS, Wu XH, Yu HG, Teng LS (2017) Tangeretin inhibits neurodegeneration and attenuates inflammatory responses and behavioural deficits in 1-methyl-4-phenyl-1,2,3,6-tetrahydropyridine (MPTP)-induced Parkinson's disease dementia in rats. Inflammopharmacology 25:471-484

Yang L, Wang H, Liu L, Xie A (2018) The role of insulin/IGF-1/PI3K/ Akt/GSK3 $\beta$ signaling in Parkinson's disease dementia. Front Neurosci 12:73

Yin F, Sancheti H, Patil I, Cadenas E (2016) Energy metabolism and inflammation in brain aging and Alzheimer's disease. Free Radic Biol Med 100:108-122

Zhang H, Wang D, Gong P, Lin A, Zhang Y, Ye RD, Yu Y (2019a) Formyl peptide receptor 2 deficiency improves cocgnition and attenuates tau hyperphosphorylation and astrogliosis in a mouse model of Alzheimer's disease. J Alzheimers Dis 67:169-179

Zhang L, Zhang L, Li L, Hölscher C (2019b) Semaglutide is neuroprotective and reduces $\alpha$-synuclein levels in the chronic MPTP mouse model of Parkinson's disease. J Parkinsons Dis 9:157-171

Zhao C, Ling Z, Newman MB, Bhatia A, Carvey PM (2007) TNF-alpha knockout and minocycline treatment attenuates blood-brain barrier leakage in MPTP-treated mice. Neurobiol Dis 26:36-46

Zhu J, Gao W, Shan X, Wang C, Wang H, Shao Z, Dou S, Jiang Y, Wang C, Cheng B (2019) Apelin-36 mediates neuroprotective effects by regulating oxidative stress, autophagy and apoptosis in MPTP-induced Parkinson's disease model mice. Brain Res 1726:146493

Zussy C, Brureau A, Delair B, Marchal S, Keller E, Ixart G, Naert G, Meunier J, Chevallier N, Maurice T, Givalois L (2011) Timecourse and regional analyses of the physiopathological changes induced after cerebral injection of an amyloid $\beta$ fragment in rats. Am J Pathol 179:315-334

Publisher's Note Springer Nature remains neutral with regard to jurisdictional claims in published maps and institutional affiliations. 